\title{
How Ethnic and Linguistic Heterogeneity Influence the Prospects for Civil Society: A Comparative Study of Citizenship...
}

Article in The Journal of Politics · November 2006

DOI: $10.1111 /$ j.1468-2508.2006.00470.x

CITATIONS

105

2 authors:

Christopher J. Anderson

Cornell University

80 PUBLICATIONS 4,350 CITATIONS

SEE PROFILE
READS

278

Aida Just

Bilkent University

14 PUBLICATIONS 236 CITATIONS

SEE PROFILE 


\title{
How Ethnic and Linguistic Heterogeneity Influence the Prospects for Civil Society: A Comparative Study of Citizenship Behavior
}

\author{
Christopher J. Anderson Cornell University \\ Aida Paskeviciute Bilkent University
}

\begin{abstract}
While the positive consequences of social capital and civil society are widely accepted and appreciated, the question of how they originate and can be sustained has received relatively little attention from scholars. In this study, we approach this question from a cross-national and individual-level perspective by examining how population heterogeneity in the form of ethnic and linguistic diversity affects citizenship behavior, measured by cognitive and interpersonal engagement about politics, membership in voluntary associations, and interpersonal trust. Based on data collected in 44 countries, our analyses show that heterogeneity does affect the quality of civil society in a country. However, indicators of population heterogeneity do not have uniformly positive or negative effects on individual-level measures of civil society - while they reduce some, they shore up others.
\end{abstract}

W hile a long stream of political science scholarship has argued that heterogeneity in populations creates political conflict and reduces the odds that democracy will thrive, relatively little is known about the consequences of heterogeneity for civil society-a critical ingredient of democratic governance. In this paper, we argue that there are theoretical and empirical reasons to believe that heterogeneity can have salutary as well as detrimental effects on civil society. Moreover, we contend that it is doubtful whether different manifestations of heterogeneity affect outcomes similarly and can therefore be used interchangeably. We investigate these claims by examining how population heterogeneity ${ }^{1}$ in the form of ethnic and linguistic differences influences citizen attitudes and behaviors associated with civil society-or what we label "citizenship behavior"—in a varied sample of countries around the globe. Our analyses show that, first, ethnic and linguistic heterogeneity are not synonymous: a number of countries that are ethnically heterogeneous are linguistically homogeneous and vice versa. This implies that it is hazardous to treat ethnicity and language as substi- tutes. The importance of distinguishing between ethnic and linguistic heterogeneity is validated further when we examine their impact on citizen behavior. Contrary to what is commonly assumed, we find that heterogeneity does not have a uniformly negative effect on all forms of citizenship behavior-while they reduce some, they shore up others. What is more, linguistic and ethnic heterogeneity has different effects in established and less democratic states. For example, while linguistic heterogeneity reduces people's interest in politics and does not significantly affect membership in voluntary associations in established democracies, it increases the odds that citizens are members of voluntary associations or express an interest in politics in less democratic countries.

Below, we begin by discussing extant research on what we know about the impact of population heterogeneity on citizenship behavior. We then make a case for the importance of distinguishing between ethnic and linguistic heterogeneity and develop a set of hypotheses regarding their effects on citizen behavior. Subsequently, we develop an estimation model that is tested with individual- and country-level data from 44

${ }^{1}$ Population heterogeneity also has been variously referred to as diversity, fractionalization, division, etc. For the purposes of this study, we will use the more general term heterogeneity.

The Journal of Politics, Vol. 68, No. 4, November 2006, pp. 783-802 
countries around the globe. A concluding section discusses the findings and their implications for our understanding of the relationship between population heterogeneity and democracy.

\section{Citizenship Behavior in Heterogeneous Countries}

Several long-standing and interrelated social science literatures address the microfoundations of democracy by focusing on issues of civil society, social capital, participatory and deliberative democracy, democratic citizenship, and democratic political culture. And while the overlaps among these literatures are obvious, the precise lines of demarcation usually are not (Bowler, Donovan, and Hanneman 2003). For the purposes of our analyses, we sidestep the debates about the limits, extent, and precise definition and interrelationship of civil society, civic involvement, social capital, citizenship, and like terms by focusing on what we label "citizenship behavior," and which we define as attitudes and behaviors thought to be conducive to high-quality civil society and representative (mass) democracy.

We distinguish between cognitive and structural aspects of citizenship behavior. ${ }^{2}$ Cognitive citizenship behavior is subjective and refers to attitudes and beliefs conducive to high-quality civil society. In contrast, structural elements of citizenship behavior facilitate mutually beneficial collective action and manifest themselves through social networks and organizations (see also Krishna and Uphoff 2002). Our analysis thus groups social capital elements of civil society conceptualized by Coleman, Putnam, and others (membership in voluntary associations and interpersonal trust), with indicators of citizenship behavior long considered to be critically important by normative and empirical democratic theorists (political interest and political discussion behavior; e.g., Almond and Verba 1963; Barber 1984; Barnes et al. 1979; Guttman and Thompson 1996; van Deth 2000; van Deth and Elff 2004). ${ }^{3}$

${ }^{2}$ We appropriate this distinction from Grootaert and van Bastelaer (2002).

${ }^{3}$ Political discussion is commonly viewed as an important, albeit potentially conflictual element of the democratic process (Fishkin 1991; Macedo 1999) that allows citizens to express their preferences, debate contentious issues, and even transform individual preferences to achieve a consensual collective decision of superior quality (Conover, Searing, and Crewe 2002; Knight and Johnson 1994). It also constitutes a crucial mechanism of political mobilization, thus helping citizens to form attitudes and engage in
A sizable literature has documented the manifold positive effects of citizenship behaviors both at the level of individuals and the level of countries. ${ }^{4}$ Such behavior provides the basis for the survival and stability of a democratic regime by helping to ensure more effective performance of political institutions (Almond and Verba 1963; Gibson 2001; Inglehart 1999; Knack 2002; Knack and Keefer 1997; La Porta et al. 1997; Muller and Seligson 1994; Newton 2001; Putnam 1993). ${ }^{5}$ Given the largely positive consequences envisioned and documented by research on citizenship behaviors and attitudes, then, an important question is how they are produced or how they can be sustained and enhanced.

Recent empirical and theoretical work suggests that a community's level of homogeneity plays a prominent role in fostering good citizenship. To be sure, the notion that a country's or community's

behaviors conducive to better democratic participation (Huckfeldt and Sprague 1995). Citizens who are interested in politics and frequently discuss it with others exhibit more coherent and structured attitudes and are more likely to participate in politics (Converse 1970; Jennings et al. 1989; van Deth 1991).

${ }^{4}$ At level of individual citizens, citizenship behaviors generate political awareness and participation, and they sustain citizens' confidence in political institutions and support for democratic processes (Brehm and Rahn 1997; Gibson 2001). Moreover, they allow citizens to overcome collective action problems because they breed cooperation and facilitate coordination among citizens (Coleman 1990; Putnam 1993, 2000). For example, membership in voluntary associations and extensive and diverse discussion networks lead to higher levels of political tolerance (Cigler and Joslyn 2002), reinforce participatory norms, encourage cooperation, and promote interpersonal trust (Brehm and Rahn 1997; Curtis, Baer, and Grabb 2001). Interpersonal trust, in turn, sustains social networks and cooperation (Brehm and Rahn 1997; Cigler and Joslyn 2002; but see Raymond 2006) and facilitates the transmission of democratic values and political information (Gibson 2001). At the level of countries, scholars have long argued that such behavior on the part of citizens has a positive influence on a country's social, political, and economic life (Almond and Verba 1963; Knack and Keefer 1997; Putnam 1993; Whiteley 2000).

${ }^{5}$ Recently, research on interpersonal trust and organizational membership has investigated whether different kinds of groups and different kinds of trust have differential effects (Bowler, Donovan, and Hanneman 2003; Stolle and Rochon 1998; Uslaner 2002), suggesting that the salutary effects of such behaviors derive not only from more associations or trust, but from the right kinds of associations and trust relationships (Bowler, Donovan, and Hanneman 2003; Uslaner 2002; see also Levi 1996). Relatedly, some have argued that the benefits of associational membership for democracy are not always obvious (cf. Stolle and Hooghe 2003; Theiss-Morse and Hibbing 2005). Regarding the salutary effects of political interest and discussion, it is worth noting that they may also serve to mobilize rather than harness undemocratic impulses, and this tendency may be more pronounced in less democratic countries. These are not questions we are able to address in our paper, but we wish to note that these findings are important and help to refine the general thesis that civic associations and interpersonal trust are good for democracy. 
degree of homogeneity matters is nothing new in comparative research and harkens back to longstanding discussions about the role of heterogeneity (e.g., in the form of ethnic divisions) in encouraging stable democratic rule or economic development (Alesina et al. 2003; Dahl 1971; Easterly and Levine 1997; Hibbs 1973; Horowitz 1985; Lijphart 1968; see also Weingast 1997). On balance, most scholars of comparative politics view population heterogeneity in a negative light, arguing that it breeds conflict that is difficult to resolve and, as a consequence, political systems that are inherently more unstable.

A varied set of literatures from political science and psychology underpin this conflict-centered view of heterogeneity. This perspective views conflict as being rooted in preferences for interaction because of material and psychological sources of conflict and opportunities for social interaction that are frequently structured by ethnicity, religion, and the like (either spatially or because of already existing networks of regular interaction). These combine to produce the expectation that people in societies marked by greater heterogeneity will be less likely to develop the attributes required of democratic citizenship than those who live in environments characterized by greater homogeneity.

The predominant view is that heterogeneous communities experience more conflict because of threats to a group's consumption of scarce resources (material threats) as well as threats to feelings of belonging to a group (psychological threats; Fearon and Laitin 1996). If we view these threats as inherently conflictual-that is, if we view material conflict as zero-sum and people's motivations to defend their in-group as requiring a view of other groups that are more negative-then it should not be surprising to find that more heterogeneous societies exhibit lower levels of cooperative and trusting behaviors (though see Bahry et al. 2005; Sniderman et al. 2000). At the microlevel, this perspective is consistent with the psychology literature on in- and out-groups (Brewer 1981; Dovidio and Gaertner 1999; Tajfel 1982), which has documented that people have an ingroup bias-a preference for members of their group as well as indifference toward members of outgroups. Moreover, people tend to see members of the ingroup as more varied in their characteristics and outgroups as more homogeneous, giving rise to stereotyping of the outgroup.

Theories of social conformity, which argue that individuals prefer to interact with others like them because of shared interests, socialization to the same cultural norms, and greater empathy toward individu- als who remind them of themselves (Gibson and Gouws 2002), also support the conflict-based view. Given that attitudes and behaviors associated with democratic citizenship often involve an individual's interaction with others, we would predict that these interactions are more or less likely or more or less pleasant, depending on a country's level of heterogeneity. Thus, as a result of preferences for interaction with like others, overall levels of interaction should be lower in more heterogeneous countries.

A sizable literature in American politics on ethnic conflict and perceptions of ethnic threat provides indirect support for the predictions following from this conflict model. In the most widely cited formulation of the so-called "power threat" or "real conflict" thesis (Bobo 1988; Key 1949), a superordinate group becomes more hostile as the size of the proximate subordinate group increases (see Oliver and Wong 2003, 568). In particular, a number of studies of blackwhite relations in the United States have found that, as black populations increase, there is a consistent increase in white racial antagonism (see, e.g., Giles and Buckner 1993; Quillian 1996; Taylor 1998).

The most direct evidence supporting the conflict model can be found in an emerging stream of research showing that homogeneity fosters higher levels of social capital and public goods provision in a community. Based on data from the United States, Alesina and La Ferrara (2000), for example, report that individuals who live in racially mixed communities are less willing to participate in social activities. Using a similar approach, Alesina and La Ferrara (2002) show that individuals living in racially more fragmented communities have a lower propensity to trust other people, while Costa and Kahn (2003) report that citizens in more racially mixed communities in the United States have lower rates of civic participation, voting, and trust. A related set of studies that make use of data collected in the United States has found that public goods are underprovided in more heterogeneous communities (Costa and Kahn 2003). And at the level of individuals, scholars also have found that "distinctive" (ethnic and linguistic) minorities are less attached to the nation-state or democracy as a form of government (Dowley and Silver 2002; Elkins and Sides 2004). Hence, there is mounting evidence that more homogenous communities have higher levels of social interactions leading to a more highly developed civil society.

The idea that heterogeneity invariably has a negative impact on people's civic attitudes and behaviors is open to both theoretical and empirical challenge, however. A contrasting perspective would lead us to 
believe that individuals in countries with more heterogeneous populations have stronger motivations to develop an interest in politics, express their views (at least among like-minded and therefore trusted compatriots), as well as participate in voluntary associations (Anderson and Paskeviciute 2005). There is reason to assume that heterogeneity can boost citizenship behaviors in part because motivations to extract and guard material benefits for the group may produce greater psychological and other involvement in politics or the desire to be organized socially. And these motivations should be particularly pronounced in more heterogeneous communities because ethnicity (or whatever the underlying dimension of variation) is liable to be more salient in heterogeneous than homogeneous countries. Because associations and networks are vehicles for articulating and aggregating interests as well as act as intermediaries between citizens and elites, greater heterogeneity (and conflict) thus might lead to more, not less, citizen involvement. Put another way, in heterogeneous societies politics may matter more because competition takes place across easily understood group lines. Conversely, in homogeneous societies preferences tend to be less dispersed and group competition less salient, and individuals can therefore be expected to derive comparatively less utility from joining with others and be politically involved since there is less of a need to promote one's distinct interests (see also Oliver and Wong 2003).

Greater variation also should spur more political discussions and political interest because citizens are likely to gain valuable and cheap information through their interactions; this, in turn, should motivate more discussions and political interest (see Huckfeldt and Sprague 1995, 54; MacKuen 1990, 71). This is consistent with writing about the positive effects of bridging relationships in the social capital literature (Putnam 2000; see also Woolcock 2001) and the contact hypothesis in the literature on ethnic conflict in the United States (Oliver and Wong 2003). Bridging contacts that involve a people from varied backgrounds of the population are seen as more beneficial for the production of generalized trust, tolerance, and a host of other civic values than sole interactions with similar people (which are more likely). Empirically, this positive effect has been confirmed in research on the effect of cross-cutting cleavages on tolerance, for example (Mutz 2002), or the effect of ethnic heterogeneity on trust (Marschall and Stolle 2004). Thus, this competing perspective emphasizes the benefits of interaction with diverse others (Bobo 1988; Welch et al. 2001).
Taken together then, and in contrast with common assumptions in the comparative literature on democracy, social capital, and civil society, this perspective would lead us to hypothesize that citizens in more heterogeneous environments will be more likely to develop at least some of the structural and cognitive manifestations of citizenship behavior. Several questions remain, however. For one, because existing (conflict-based) microlevel theories focus on understanding people's feelings about their own or other groups, they actually have little to say about how heterogeneity affects citizenship behavior. Moreover, this literature assumes that the heterogeneity of a country is experienced similarly within and across countries. Keeping in mind that we are interested in the effects of heterogeneity cross-nationally, rather than intracountry political dynamics, existing theories are silent on the question of whether and how heterogeneity aggregates up to produce an effect at the level of countries. We suspect that, given differential patterns of ethnic and other kinds of segregation across countries, some kinds of heterogeneity in some contexts make high levels of citizenship behavior more likely within some countries, but the same may not hold across countries.

Unfortunately, the empirical evidence for adjudicating among the different perspectives on the connection between heterogeneity and civil society is limited. Comparative studies of the effects of heterogeneity on civil society attitudes and behaviors are rare; and what is more, they do not usually examine indicators of civil society directly. One of the few cross-national studies is Costa and Kahn's (2003) investigation of the correlation between ethnic heterogeneity and associational membership across countries in Western Europe. While their evidence fails to show any evidence of a relationship between heterogeneity and rates of membership, it is possible that any aggregate-level correlation between population heterogeneity and citizenship behaviors (or lack thereof) may hide important intra- and cross-country variation that, once accounted for, may help us to identify the relationship's proper strength and direction. And beyond Western Europe, there are no cross-national studies linking population heterogeneity and citizenship behaviors, though some suggestive evidence can be found in the case-study literature based on cases from the developing world. These studies generally conclude that heterogeneity has negative effects on civil society and the provision of public goods. ${ }^{6}$

${ }^{6}$ For example, in a study of communities in Peru, Karlan (2002) found that default rates on microfinance loans are higher in communities that are culturally dissimilar, and Miguel and Gugerty 
Taken together, then, we would argue that the empirical record is open to critical challenges regarding the relationship between heterogeneity and civil society at the cross-national level. For one, the effects of heterogeneity have been investigated most systematically with data from various communities within the United States. Moreover, the effect of heterogeneity usually has not been examined on citizenship behaviors and attitudes directly in a cross-national setting. Finally, because the sample of countries considered in these studies has been limited to the United States or single countries in the developing world, it is uncertain whether heterogeneity is associated with the quality of democratic citizenship in a large and varied sample of countries representing varying levels of wealth and different political cultures.

\section{Ethnicity and Language: Two Sides of the Same Coin?}

While population heterogeneity can manifest itself in different forms, scholars of democracy, civil society, and civil conflict most commonly investigate population heterogeneity with an eye toward ethnic heterogeneity (Alesina and Ferrara 2005). Empirically speaking, researchers have commonly used language as a proxy for ethnic variation in a country (Laitin 2000a) and have utilized so-called measures of "ethnolinguistic fractionalization" to capture variability within a population along ethnic lines. The problems with this approach are myriad and discussed with great care by Laitin (2000a). Suffice it to say for our purposes that using language as a proxy for ethnicity or relying exclusively on ethnicity or language to measure population heterogeneity is likely to miss important dimensions of variation within a population for two reasons: First, it assumes that ethnicity maps onto language one-for-one (Alesina and Ferrara 2005); second, it assumes that language has the same consequences for citizenship behaviors as ethnicity. Both assumptions, we would argue, are likely to be problematic (see also Posner 2004).

(2005) report that school funding in Kenya is lower in communities that are more ethnically diverse. La Ferrara (2002) finds that income inequality is associated with lower group participation in rural Tanzania. And a recent study by Barr (2004) who conducted field experiments in Zimbabwe exploiting the resettlement policies promoted by the government, revealed that socially and ethnically heterogeneous villages were less likely to trust compared with nonresettled communities. She concluded that the lower propensity to trust among resettled villagers was due to the lower density of kinship ties rather than to differences in altruism or socially transmitted norms.
Examining the first assumption requires separate measures of ethnic and linguistic heterogeneity for a range of countries. We rely on the indicator most commonly used in the existing literature on ethnic diversity, the "fractionalization index" (also called the Hirschman-Herfindahl index). This measure is defined as follows:

$$
\text { Heterogeneity }=1-\sum_{i} s_{i}^{2}
$$

where $s_{i}$ is the share of group $i$ over the total of the population. The measure has an intuitive interpretation and denotes the odds that two individuals randomly picked from the population belong to different groups (see Alesina and Ferrara 2005). ${ }^{7}$ The measure ranges from 0 for countries with no heterogeneity to a theoretical maximum of 1 when every individual belongs to a different group. ${ }^{8}$

Our second independent variable of interest is linguistic heterogeneity. We use the linguistic diversity index provided by the Ethnologue project that is based on information about 6,800 languages around the world (Gordon 2005). ${ }^{9}$ Calculated as a fractionalization index as well, the Ethnologue linguistic diversity

${ }^{7}$ We rely on the original sources, mainly the CIA World Factbook and the Encyclopedia Britannica, to obtain data on the ethnic composition of each country in our sample. This approach, also adopted by Alesina et al. (2003), does not take a stand on whether some ethnic groups are more relevant than others and is based on the assumption that ethnic groups are "objective categories" into which individuals can be classified, and that such classifications are commonly shared and exogenous.

${ }^{8}$ An alternative measure of ethnic heterogeneity, a so-called "polarization index," was devised by Garcia Montalvo and Reynal-Querol (2005) to predict civil conflict, drawing on the expectation that civil wars are more likely to occur when a society is composed of two equally sized ethnic groups rather than of many small groups. The index reaches the maximum value when two equally sized groups face each other and declines as the configuration of groups diverges from this half-and-half split. The authors show that this index is highly correlated with ethno-linguistic fractionalization at low levels of fractionalization, uncorrelated at intermediate levels, and negatively correlated at high levels. In a subsequent study Alesina at al. (2003) compared the polarization index and fractionalization index and found that the fractionalization works better as a determinant of policies and economic outcomes. Given that the characteristics of democratic citizenship or civic capital are closer to the nature of economic outcomes (if we conceive of civil society as a public good), we rely on the fractionalization index rather than a polarization index as a measure of heterogeneity.

${ }^{9}$ The Ethnologue linguists use a branching method in constructing their data - that is, they rely on linguistic trees, classifying languages by structure, with branch points for language family (e.g., IndoEuropean from Afro-Asiatic), language groups, and down to the level of subdialects. This makes the Ethnologue data sensitive to distance among languages, and the measure of linguistic diversity is based on languages that are truly distinct linguistic entities. Given the purposes of our study, this measure provides a functional, 
index represents "the probability that any two people in the country picked at random will have different mother tongues" (see The Ethnologue: Introduction). ${ }^{10}$

Our study of citizen attitudes and behavior relies on individual-level survey data from 44 countries with widely divergent political systems, cultures, histories, and practices (see the online appendix at http://www. journalofpolitics.org for a list of countries). If substituting language heterogeneity for ethnic heterogeneity is safe practice empirically speaking, then we should find a reasonably close correlation between the two indicators across countries. Figure 1, which plots the degree of ethnic and linguistic heterogeneity across the countries included in this study, allows us to examine whether this is indeed the case.

As the graph reveals, language is indeed an excellent proxy for ethnicity in countries as different as Uganda (in the upper-right corner, which scores .93 and .92 on the language heterogeneity index and the ethnic heterogeneity index, respectively), Macedonia (in the middle of the distribution, scoring .49 and .50), or Denmark (in the lower left-hand corner, scoring .05 and .06). Yet, and equally important, for a number of countries levels of ethnic heterogeneity and linguistic heterogeneity vary significantly. Thus, Mexico, for example, scores low on linguistic heterogeneity (.13), but quite high (.54) on ethnic heterogeneity. Conversely, the Philippines and Tanzania score extremely high on linguistic heterogeneity, but very low on ethnic heterogeneity. What is more, Mexico, the Philippines, and Tanzania are far from exceptional as a

readily available, and cross-nationally comparable measure of linguistic divisions within countries. Using data from the Ethnologue as the source for linguistic country composition to calculate diversity for the purpose of our study is equivalent to using the Encyclopedia Britannica or the CIA Factbook (the latter, however, provides country breakdowns for only a small set of cases): Alesina et al. (2003) report the linguistic fractionalization index using these alternative sources and find a high correlation between the indicators.

${ }^{10}$ Laitin (2000a) spells out important shortcomings of the existing data on linguistic country composition. He argues that the preferred measure of linguistic community is not the probability that any two people in the country picked at random will have the same mother tongues, but the probability that any two people in the country picked at random will have at least one language in common (Laitin 2000a, 149; emphasis added). What makes linguistic diversity distinct from ethnic heterogeneity is that some individuals are multilingual and able to communicate with others even when their mother tongues are different. A measure of linguistic heterogeneity should therefore be designed to capture citizen communication possibilities in a country. While such a measure would be ideal for the purpose of our analysis, it is not available because it needs to be constructed using newly developed databases (Laitin 2000a). Thus, our measure is perhaps second best, when viewed from a conceptual perspective, but the best measure currently available on country linguistic compositions.

\section{FIgURE 1 Ethnic and Linguistic Heterogeneity in 44 Countries}

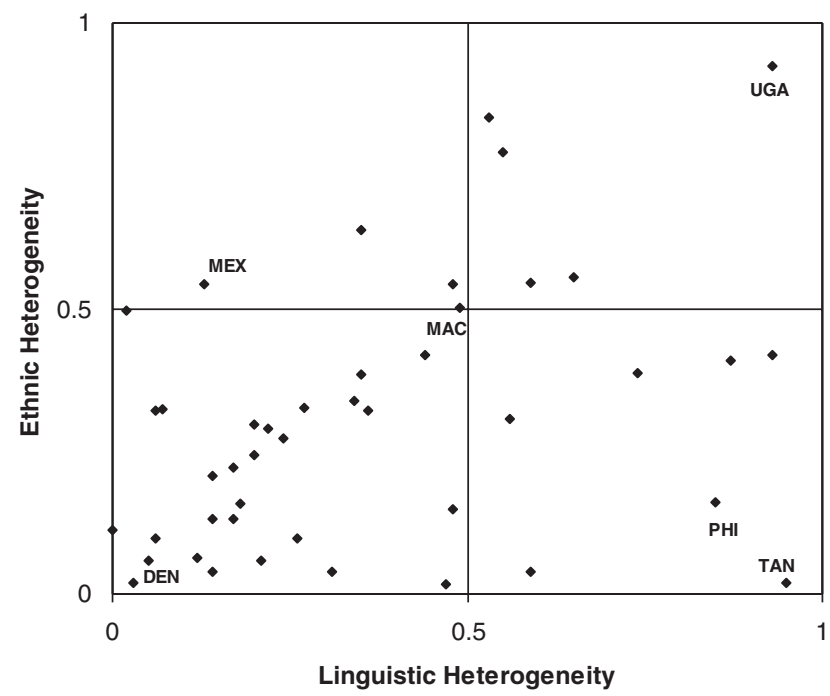

Sources: Ethnic heterogeneity: Calculated by authors from CIA World Factbook and Encyclopedia Britannica. Linguistic heterogeneity: Gordon (2005).

number of states are either ethnically heterogeneous or linguistically heterogeneous, but usually not both. Thus, while the overall correlation between ethnic and linguistic heterogeneity is positive, it is modest (Pearson's $\mathrm{r}$. $.38 ; p=.011) .{ }^{11}$

These results lead to the unambiguous inference that ethnic heterogeneity is frequently not synonymous with linguistic heterogeneity. And this, we posit, has important implications for understanding the impact of population heterogeneity on civil society behaviors. For one, it means that these two dimensions of heterogeneity at a minimum require empirical separation. Moreover, they require that we entertain the possibility that these dimensions of heterogeneity have independent effects on attitudes and behaviors. That is, perhaps it is the case that language and ethnicity both matter, and that they do so separately and in different ways.

Two perspectives guide our expectations as to the different effects ethnic and linguistic heterogeneity may have on citizenship behaviors. The first centers on the extent to which heterogeneity impedes efficiency in social interactions - that is, across group lines. Specifically, to the extent that language facilitates social interaction, we would expect the impact of linguistic heterogeneity to be more pronounced and negative with regard to structural citizenship behaviors than

\footnotetext{
${ }^{11}$ Another way to think about this correlation is to say that one
} variable explains $14 \%$ of the variation in the other $\left(.38^{2}\right)$. 
cognitive ones. That is, we expect linguistic heterogeneity to have a greater and negative effect on citizenship behaviors that require social interaction and communication (political discussion and associational membership) than those that do not (political interest, trust).

An alternative perspective centers on the mobilizing effects of heterogeneity. If heterogeneity mobilizes societies politically, it is more likely to boost intrinsically political behaviors-such as talking about politics and being cognitively involved in politics - than behaviors that are not primarily political in naturebeing a member of a voluntary organization or trusting others. In contrast, greater ethnic heterogeneity may mean smaller recognizable communities, and greater linguistic heterogeneity may mean greater efficiency in mobilizing smaller groups of people who speak a common language for collective action (see also Alesina and Spolaore 2003). As a consequence, greater linguistic and ethnic heterogeneity should produce greater efficiency within groups and aid in recruiting members of voluntary associations and building political discussion networks.

Finally, we posit that heterogeneity is likely to have different consequences for citizenship behaviors, depending on countries' experience with democracy. This expectation derives from the real-world observation that heterogeneity is more likely to trigger conflict and mobilization along ethnic or linguistic lines in undemocratic or newly democratized states than mature democracies. This mobilization may lead to increased demands for democratic reforms, but it may also undermine democracy, as the examples of the former Yugoslavia and a number of the post-Soviet republics demonstrate. There are numerous other examples of turmoil caused by heterogeneity in Latin America and Africa as well. Such states have usually not achieved equilibrium conditions of democratic stability, and citizens have not been habituated to democratic behavior.

Moreover, people in heterogeneous societies have more reasons to mobilize and follow politics if they live in semi- or non-democracies because fundamental issues are at stake in these political systems. In contrast, research shows that citizens in established democracies tend to consider politics unimportant to them, or at least much less important than other aspects of life such as family, work, friends, leisure time, or religion (e.g., van Deth 2000). In such an environment, political entrepreneurs have more limited opportunities to exploit social divisions for political ends. And unlike mature democracies, semior non-democracies do not have established political institutions to accommodate competing demands, or norms to ensure respect even for basic rights of other ethnic or linguistic groups (especially if those groups are in the minority). Thus, the extent to which the interests of various groups in heterogeneous societies succeed might be directly related to citizen mobilization and political engagement.

This implies that heterogeneity should matter less powerfully in countries that are anchored in political cultures that prize active citizenship and that have achieved equilibrium conditions of stable democratic rule than in countries where the status quo is far from settled. It does not imply, however, that heterogeneity should be associated with lower levels of citizenship behavior. If heterogeneity produces greater efficiency and political divisions are mobilized within numerous small communities, we would expect heterogeneity to be associated with higher levels of cognitive and structural citizenship behavior.

\section{Multivariate Analyses: Data and Measures}

Research that investigates the impact of individual differences and variation in national contexts on the behavior of individuals requires a cross-national research design. The data analyzed here include both individual-level and aggregate-level information. Our individual-level data come from surveys collected as part of the World Values Surveys (WVS) in 1999-2001 (Inglehart et al. 2000). The 44 countries that provided most important survey items and that had a sufficient number of cases for multivariate analysis are drawn from all continents and vary widely in their political, economic, social, and historical characteristics (see online appendix $).{ }^{12}$

\section{Dependent Variables}

The individual level dependent variables include two structural measures of citizenship behavior (frequency

\footnotetext{
${ }^{12} \mathrm{~A}$ number of countries in the WVS had to be dropped due to missing values on important variables. Some or all of the organizational membership variables were missing for Algeria, Azerbaijan, Australia, Armenia, Brazil, Taiwan, Colombia, Dominican Republic, El Salvador, Georgia, Indonesia, Iran, Jordan, Korea, The Netherlands, Nigeria, Norway, Switzerland, Egypt, Uruguay, Turkey, and Pakistan. Political interest was missing for Croatia, Estonia, El Salvador, Hungary, Latvia, Malta, Romania, Slovakia, and Sweden. Income was missing for Norway and Portugal. Finally, Bosnia and Herzegovina, Northern Ireland, Serbia, Montenegro, and Puerto Rico were missing critical macrolevel variables (economic performance, heterogeneity, or both).
} 
of political discussions and involvement in voluntary organizations) and two cognitive indicators (interpersonal trust and political interest). These measures have been used widely in research on political behavior for a variety of purposes. We coded these variables such that higher values indicated a more positive response (greater interest and trust, more discussion and membership). For details on question wording and coding, see the online appendix. ${ }^{13}$

\section{Independent Variables: Ethnic and Linguistic Heterogeneity}

Our key independent variables are ethnic and linguistic heterogeneity in the form of "fractionalization" indices (the Hirschman-Herfindahl index) described above and commonly used in the existing literature on population heterogeneity. ${ }^{14}$

\section{Control Variables}

Like other forms of political behavior, involvement in political discussions, interest in politics, participation in voluntary organizations, and interpersonal trust have often been studied at the level of individuals. A number of demographic and attitudinal factors have been found to affect political involvement and engagement and are therefore controlled for in our models (for details on variables, see online appendix). Generally speaking, citizens are more likely to engage in a variety of modes of political participation if they have the necessary resources and motivations to get involved. The most prominent proxy for resources is socioeconomic resource level (Verba, Schlozman, and Brady 1995). A substantial literature has documented that higher levels of education and social status (measured by income or class) are the most consistently significant predictors of political action across a variety of countries (Almond and Verba 1963; Barnes et al. 1979; Jennings et al. 1989; Nie, Verba, and Kim 1971).

In addition, scholars have found age and sex to be important predictors of political participation. Both can be categorized under the rubric of the (socioeconomic) resource model of participation (Leighley 1995; Verba, Schlozman, and Brady 1995). This

\footnotetext{
${ }^{13}$ All four dependent variable indicators are correlated positively with one another in our sample of countries, with individual-level correlations of similar magnitude.

${ }^{14}$ For our sample of countries, the correlation between this measure and the Alesina et al. (2003) measures of ethnic and linguistic heterogeneity are $.830(p<.0001)$ for ethnic heterogeneity and $.826(p<.0001)$ for linguistic heterogeneity.
}

research suggests that increased social responsibilities tend to go along with increased motivations to become politically active (Nie, Verba, and Kim 1971; Jennings and Niemi 1981) ${ }^{15}$ Researchers also have found across a number of democracies that men are more likely to have the resources needed to engage in political acts (Dalton 2002) and that gender stereotypes contribute to a greater proclivity of men to engage in political discussions (Hansen 1997; Jennings 1983). We therefore included a control variable for gender in our models of citizenship behavior.

We also included a variable that measured respondents' religious backgrounds to capture cultural differences, possible effects of religious mobilization, and religious heterogeneity across countries. And while we are unable to discern the degree to which the individual's local environment is heterogeneous, we are able to indirectly capture aspects of respondents' location in, or attachment to, their immediate environment by including a variable for size of town and an individual's attachment to his or her local community or region. On average, larger communities are more heterogeneous, and individuals more attached to their community may be more likely to be mobilized, especially in heterogeneous environments. We therefore expected those living in smaller towns and who were more attached to their local community to exhibit higher levels of citizenship behaviors (cf. Leighley 1990).

At the macrolevel, existing literature suggests controlling for a country's level of economic development (measured by the GDP per capita) ${ }^{16}$ and economic performance (annual percentage of GDP growth), as participation rates and involvement tend to increase with higher levels of development and better economic conditions (Almond and Verba 1963; Brehm and Rahn 1997; Curtis, Baer, and Grabb 2001; Inglehart and Baker 2000; Lipset 1994). In addition, we account for state intervention in the economy as a factor that might stimulate citizens' political interest, discussions, or engagement in voluntary organizations to affect the nature of state intervention (see van Deth 1991; van Deth and Elff 2004). Finally, given that our sample includes 44 countries with a wide range of political regimes, we included a variable to measure a

\footnotetext{
${ }^{15} \mathrm{To}$ account for the possibility that the relationship between age and citizenship behaviors is curvilinear, we created three dummy variables for respondents' age, using 35-54 old as a reference category in our models because we expect this age category to represent the high point of civic engagement over the life cycle.

${ }^{16}$ Across the countries included in our study, this variable is likely to capture modernization infrastructure, as in the availability of telecommunications, as well.
} 
country's level of democratic development with the help of the Polity IV data set. Coding procedures and descriptive statistics for all variables are listed in the appendix.

\section{Analysis and Results}

Our analysis proceeds in two steps. First, we examine the impact of heterogeneity on citizenship behaviors in our full sample of countries. Second, we analyze whether the impact of heterogeneity varies between established and weak democracies. Because our analysis requires combining information collected at the level of the individual and at the level of countries, our dataset has a multilevel structure (one level, the individual, is nested within the other, the country). Ignoring the multilevel nature of the data could create a number of statistical problems (clustering, nonconstant variance, underestimation of standard errors, etc.; cf. Steenbergen and Jones 2002). We therefore estimated a maximum-likelihood multilevel regression model with random intercepts.

\section{Cross-National Models of Citizenship Behavior: Pooled Models}

Table 1 presents the results of models estimating the effects of ethnic and linguistic heterogeneity on levels of political discussion, organizational membership, political interest, and interpersonal trust across the 44 countries. The results indicate that heterogeneity matters relatively little once we control for differences across countries and individuals. Specifically, there is no effect of either ethnic or linguistic heterogeneity on the frequency of political discussion or citizens' level of political interest. And while we find that linguistic heterogeneity has a positive effect on organizational membership, this result is statistically significant only at the .10 level (one-tailed). The results imply that moving from the linguistically most homogeneous to the most heterogeneous society increases membership in voluntary associations by .5 (the mean number of associations respondents reported belonging to was 1.9 , with a standard deviation of 1.75).

The dependent variable most significantly affected by heterogeneity is trust: the results show that linguistic heterogeneity significantly reduces interpersonal trust. Calculations show that respondents' odds of exhibiting a trusting attitude decrease from .33 in a completely homogeneous country to .21 in a completely heterogeneous one (mean: .27). Moreover, the coefficient for ethnic heterogeneity is negative as well, but statistically significant only at the .1 level (onetailed). Moving from the ethnically most homogeneous country in our sample to the most heterogeneous one decreases the odds of a trusting attitude by $10 \%$ from .31 to .21 .

Taken together, these analyses for the full sample suggest that ethnic and linguistic heterogeneity have only modest effects on citizenship behavior. And when they do matter, they have both positive and negative effects. Specifically, we find that linguistic heterogeneity slightly increases membership in voluntary associations. Moreover, the results show that linguistic heterogeneity, and to a slightly lesser extent ethnic heterogeneity, reduce trust. While these latter results for the effect of heterogeneity on trust are consistent with received wisdom, the positive effects on organizational membership are not. ${ }^{17}$ Also novel is the finding that heterogeneity rooted in language appears to matter more than heterogeneity based on ethnicity. Perhaps most surprising, given existing research, when considered in global perspective ethnic heterogeneity matters less for civil society than is commonly believed. ${ }^{18}$

These results should be considered in context. Looking at the coefficients for the country level control variables, we find that most of them do not achieve conventional levels of statistical significance either (at the .05 level, using a two-tailed test of significance). The only measure of citizenship that is significantly affected by macrolevel factors is trust, as countries with higher GDP per capita, a greater government share of GDP, and well-performing economies exhibit higher levels of interpersonal trust. In contrast, we find that level of democracy has a negative effect on trust, though these effects are substantively negligible. While some of the other macrolevel controls jump the hurdle when we use less demanding tests of statistical significance, these effects are modest in size as well. Thus, with the sole exception of interpersonal trust, citizenship behaviors are not very powerfully affected by cross-national factors, such as level of development and democracy, size of the state, or even macroeconomic performance.

\footnotetext{
${ }^{17}$ Unfortunately, our survey measures do not allow us to examine the scope and nature of people's immediate political community whose members an individual might be particularly likely to join with to form associations. Thus, it is impossible for us to tell whether this effect is a sign of efficiency or mobilization.

${ }^{18}$ To further buttress these results, we performed additional analyses aimed at establishing whether these results are dependent on people's interest in politics. That is, we examined the effects of heterogeneity separately on politically interested and noninterested individuals. The results from these analyses showed no differences across these groups of respondents.
} 
TABLE 1 Multivariate Models of Citizenship Behavior in 44 Countries

\begin{tabular}{|c|c|c|c|c|}
\hline Independent Variables & Political Discussion & Membership & Political Interest & Interpersonal Trust \\
\hline \multicolumn{5}{|l|}{ Fixed Effects } \\
\hline Ethnic heterogeneity & $\begin{array}{l}.018 \\
(.107)\end{array}$ & $\begin{array}{c}-.231 \\
(.496)\end{array}$ & $\begin{array}{l}-.103 \\
(.224)\end{array}$ & $\begin{array}{c}-.102 \dagger \\
(.070)\end{array}$ \\
\hline Linguistic heterogeneity & $\begin{array}{c}-.045 \\
(.095)\end{array}$ & $\begin{array}{l}.603 \dagger \\
(.440)\end{array}$ & $\begin{array}{l}.085 \\
(.198)\end{array}$ & $\begin{array}{c}-.125^{\star *} \\
(.062)\end{array}$ \\
\hline \multicolumn{5}{|l|}{ Micro-level controls } \\
\hline Local/regional identity & $\begin{array}{l}-.041^{* * *} \\
(.006)\end{array}$ & $\begin{array}{l}-.042^{\star \star} \\
(.016)\end{array}$ & $\begin{array}{l}-.085^{\star * *} \\
(.009)\end{array}$ & $\begin{array}{l}-.016^{\star * *} \\
(.004)\end{array}$ \\
\hline Male & $\begin{array}{l}.194^{* * *} \\
(.005)\end{array}$ & $\begin{array}{l}.084^{\star * *} \\
(.013)\end{array}$ & $\begin{array}{l}.290^{* * *} \\
(.007)\end{array}$ & $\begin{array}{l}.006^{*} \\
(.003)\end{array}$ \\
\hline Age $15-34$ & $\begin{array}{l}-.112^{\star * *} \\
(.006)\end{array}$ & $\begin{array}{l}-.128^{\star * *} \\
(.015)\end{array}$ & $\begin{array}{l}-.147^{\star * *} \\
(.009)\end{array}$ & $\begin{array}{l}-.030^{* * *} \\
(.004)\end{array}$ \\
\hline Age 55-98 & $\begin{array}{l}.019^{* *} \\
(.007)\end{array}$ & $\begin{array}{c}-.019 \\
(.017)\end{array}$ & $\begin{array}{l}.108^{\star * *} \\
(.010)\end{array}$ & $\begin{array}{l}.004 \\
(.005)\end{array}$ \\
\hline High education & $\begin{array}{l}.373^{* * *} \\
(.008)\end{array}$ & $\begin{array}{l}.731^{* * *} \\
(.020)\end{array}$ & $\begin{array}{l}.507^{* * *} \\
(.011)\end{array}$ & $\begin{array}{l}.126^{* * *} \\
(.006)\end{array}$ \\
\hline Medium education & $\begin{array}{l}.198^{\star * *} \\
(.006)\end{array}$ & $\begin{array}{l}.304^{* * *} \\
(.016)\end{array}$ & $\begin{array}{l}.249^{* * *} \\
(.009)\end{array}$ & $\begin{array}{l}.045^{\star * *} \\
(.004)\end{array}$ \\
\hline Top income & $\begin{array}{l}.111^{* * *} \\
(.012)\end{array}$ & $\begin{array}{l}.371^{* * *} \\
(.030)\end{array}$ & $\begin{array}{l}.172^{* * *} \\
(.017)\end{array}$ & $\begin{array}{l}.071^{* * *} \\
(.008)\end{array}$ \\
\hline High income & $\begin{array}{l}.065^{* * *} \\
(.009)\end{array}$ & $\begin{array}{l}.225^{\star * *} \\
(.023)\end{array}$ & $\begin{array}{l}.111^{\star * *} \\
(.013)\end{array}$ & $\begin{array}{l}.034^{\star * *} \\
(.006)\end{array}$ \\
\hline Medium income & $\begin{array}{l}.021^{\star *} \\
(.009)\end{array}$ & $\begin{array}{l}.072^{* * *} \\
(.021)\end{array}$ & $\begin{array}{l}.064^{* * *} \\
(.012)\end{array}$ & $\begin{array}{l}.009 \dagger \\
(.006)\end{array}$ \\
\hline Low income & $\begin{array}{c}-.011 \\
(.010)\end{array}$ & $\begin{array}{c}-.011 \\
(.024)\end{array}$ & $\begin{array}{l}.033^{\star *} \\
(.013)\end{array}$ & $\begin{array}{c}-.001 \\
(.007)\end{array}$ \\
\hline Student & $\begin{array}{l}-.052^{* * *} \\
(.010)\end{array}$ & $\begin{array}{l}.160^{\star * *} \\
(.026)\end{array}$ & $\begin{array}{l}.030^{* *} \\
(.014)\end{array}$ & $\begin{array}{l}.037^{\star * *} \\
(.007)\end{array}$ \\
\hline Large town & $\begin{array}{l}.015^{\star *} \\
(.007)\end{array}$ & $\begin{array}{l}-.067^{\star * *} \\
(.018)\end{array}$ & $\begin{array}{l}.034^{\star * *} \\
(.010)\end{array}$ & $\begin{array}{l}-.032^{\star * *} \\
(.005)\end{array}$ \\
\hline Medium town & $\begin{array}{c}-.011 \dagger \\
(.007)\end{array}$ & $\begin{array}{c}-.014 \\
(.018)\end{array}$ & $\begin{array}{c}-.008 \\
(.010)\end{array}$ & $\begin{array}{l}-.027^{\star * *} \\
(.005)\end{array}$ \\
\hline Catholic & $\begin{array}{l}.012 \\
(.008)\end{array}$ & $\begin{array}{l}.232^{\star * *} \\
(.020)\end{array}$ & $\begin{array}{l}.034^{\star *} \\
(.011)\end{array}$ & $\begin{array}{c}-.004 \\
(.006)\end{array}$ \\
\hline Protestant & $\begin{array}{r}-.020^{*} \\
(.011)\end{array}$ & $\begin{array}{l}.457^{* * *} \\
(.028)\end{array}$ & $\begin{array}{l}.033^{\star *} \\
(.016)\end{array}$ & $\begin{array}{l}.011 \dagger \\
(.008)\end{array}$ \\
\hline Muslim & $\begin{array}{c}.024^{*} \\
(.014)\end{array}$ & $\begin{array}{l}.293^{* * *} \\
(.040)\end{array}$ & $\begin{array}{l}.046^{\star *} \\
(.019)\end{array}$ & $\begin{array}{l}.018^{\star} \\
(.010)\end{array}$ \\
\hline Orthodox & $\begin{array}{l}.044^{\star * *} \\
(.014)\end{array}$ & $\begin{array}{l}.071^{\star \star} \\
(.034)\end{array}$ & $\begin{array}{l}.048^{\star *} \\
(.019)\end{array}$ & $\begin{array}{c}-.009 \\
(.009)\end{array}$ \\
\hline Other religion & $\begin{array}{c}-.016 \dagger \\
(.011)\end{array}$ & $\begin{array}{l}.436^{* * *} \\
(.027)\end{array}$ & $\begin{array}{c}-.003 \\
(.015)\end{array}$ & $\begin{array}{l}.023^{\star *} \\
(.007)\end{array}$ \\
\hline \multicolumn{5}{|l|}{ Macro-level controls } \\
\hline $\begin{array}{l}\text { GDP per capita (in } 1,000 \text { s of } \\
\text { \$s) }\end{array}$ & $\begin{array}{r}-.004 \dagger \\
(.003)\end{array}$ & $\begin{array}{l}.017 \dagger \\
(.012)\end{array}$ & $\begin{array}{l}.005 \\
(.005)\end{array}$ & $\begin{array}{l}.003 \dagger \\
(.002)\end{array}$ \\
\hline Economic growth (in \%) & $\begin{array}{l}.002 \\
(.007)\end{array}$ & $\begin{array}{l}.014 \\
(.032)\end{array}$ & $\begin{array}{l}.010 \\
(.014)\end{array}$ & $\begin{array}{l}.015^{* * *} \\
(.004)\end{array}$ \\
\hline Expenditure (in \% of GDP) & $\begin{array}{l}.005 \\
(.005)\end{array}$ & $\begin{array}{r}-.040 \dagger \\
(.025)\end{array}$ & $\begin{array}{l}-.002 \\
(.011)\end{array}$ & $\begin{array}{l}.012^{\star * *} \\
(.004)\end{array}$ \\
\hline Polity & $\begin{array}{l}.001 \\
(.005)\end{array}$ & $\begin{array}{l}-.001 \\
(.022)\end{array}$ & $\begin{array}{r}-.015 \dagger \\
(.010)\end{array}$ & $\begin{array}{r}-.005^{\star} \\
(.003)\end{array}$ \\
\hline Intercept & $\begin{array}{l}.582^{\star * *} \\
(.121)\end{array}$ & $\begin{array}{c}.934^{\star} \\
(.555)\end{array}$ & $\begin{array}{l}1.148^{\star * *} \\
(.251)\end{array}$ & $\begin{array}{c}.133^{*} \\
(.079)\end{array}$ \\
\hline \multicolumn{5}{|l|}{ Random Effects } \\
\hline $\begin{array}{l}\text { Variance of random intercept } \\
\text { between countries }\end{array}$ & $\begin{array}{l}.021 \\
(.005)\end{array}$ & $\begin{array}{l}.448 \\
(.097)\end{array}$ & $\begin{array}{l}.091 \\
(.020)\end{array}$ & $\begin{array}{l}.009 \\
(.002)\end{array}$ \\
\hline Within-country variance & $\begin{array}{l}.388 \\
(.002)\end{array}$ & $\begin{array}{l}2.412 \\
(.014)\end{array}$ & $\begin{array}{l}.752 \\
(.004)\end{array}$ & $\begin{array}{l}.180 \\
(.001)\end{array}$ \\
\hline $\mathrm{N}$ & 60,663 & 60,493 & 60,736 & 59,352 \\
\hline Wald test $\left(\chi^{2}(24)\right)$ & $5,322.56$ & $2,707.54$ & $5,344.48$ & 986.08 \\
\hline
\end{tabular}

Note: Results are mixed-effects maximum likelihood estimates using STATA 9.0's xtmixed command. Numbers in parentheses represent standard errors. Reference categories for dummy variables are: age 35-54, low education, unreported income, small town, non-religious. $\dagger^{\dagger}<.1$ (one-tailed); ${ }^{\star} p<.1$ (two-tailed); ${ }^{* *} p<.05$ (two-tailed); ${ }^{* *} p<.001$ (two-tailed). 
Instead, these behaviors are most consistently affected by individual differences. The estimations reveal that, among the individual-level controls, education and income, as well as having a strong allegiance to one's locality or region, have the most reliable impact: in line with previous studies, the most highly educated individuals and those with higher incomes exhibit the highest levels of all attitudes and behavior associated with both structural and cognitive indicators of citizenship. But we also find that those whose allegiances are at the local or subnational level exhibit significantly lower levels of citizenship behaviors.

Furthermore, age has the expected positive effect on citizenship behaviors, with younger individuals reporting lower levels of citizenship behaviors. Finally, living in a large town is associated with higher levels of political discussion and interest, but lower levels of organizational membership and trust, and living in a medium-sized town is associated with lower levels of trust and political discussion (at the .1 level, onetailed) as well. Finally, more religious individualsregardless of faith tradition-report more involvement in voluntary associations and interest in politics than individuals who report not being religious. The only exception to this pattern is the slightly lower level of political discussion among Protestants relative to nonbelievers. Moreover, Muslims have higher levels of all citizenship behaviors than individuals who are not religious. The other individuallevel control variables exhibit inconsistent effects, and we will not comment on them further here.

Speaking very generally, at a minimum these findings suggest that heterogeneity matters, but also speak to the need to consider the separable effects of different kinds of heterogeneity on citizenship behavior. The analysis so far shows that a country that is linguistically heterogeneous is more likely to have a citizenry marked by high levels of organizational membership, but also one with lower levels of interpersonal trust. In contrast, the frequency of political discussion or levels of political interest do not appear to be affected in countries that are high on either dimension of heterogeneity.

\section{Heterogeneity and Citizenship Behavior: Established and Weak Democracies}

As a further test of the hypothesis that different types of heterogeneity matter and do so separately, as well as a test of our expectation that citizenship behavior may be affected more powerfully in weak democracies-that is, that there is an interaction between level of democratic development and level of heterogeneity-we examined the impact of ethnic and linguistic heterogeneity on citizenship behaviors separately in established democracies and weak democracies or nondemocracies. ${ }^{19}$ Tables 2 and 3 show the results.

The results reveal a much more differentiated picture than the analysis of the pooled sample. Specifically, we find that the effects of heterogeneity depend on the level of democracy. It turns out that heterogeneity matters relatively little in established democracies. And when it does matter, it has a negative effect on citizenship behaviors. Specifically, linguistic heterogeneity reduces political interest, and ethnic heterogeneity reduces interpersonal trust in established democracies. In contrast, linguistic heterogeneity significantly increases organizational membership and levels of political interest in less democratic countries, while at the same time reducing levels of interpersonal trust. Consistent with this, we find that ethnic heterogeneity stimulates political discussion in less democratic societies. Put another way, then, heterogeneity stimulates interest in and conversation about politics in weak democracies, but diminishes political interest in established ones. And while linguistic heterogeneity boosts membership in voluntary associations in weak democracies, it has no such effect in established democracies.

At the same time, heterogeneity has a negative effect on trust in both weak and established democracies. Yet, here, too, the culprits differ: in the established democracies, ethnic heterogeneity reduces trust, while it is linguistic heterogeneity that lessens trust in less democratic countries.

\footnotetext{
${ }^{19}$ Another way of testing the hypothesis that there is an interactive effect of level of democracy and heterogeneity on citizenship behavior would be to employ interaction terms. However, given that the interactions are hypothesized to exist at the macrolevel (with a relatively small $\mathrm{N}$ at that level of analysis), and because this kind of analysis would involve at least two interaction terms, we decided to employ a split-sample analysis (see also Hanushek and Jackson $(1977,150)$ for a discussion of the estimation issues involved in this type of analysis). We divided our sample of countries into established democracies and weak democracies or nondemocracies on the basis of their scores in the Polity IV data set. Countries were considered established democracies if they had a score of 10 on the Polity score in the Polity IV data set. These included Austria, Belgium, Canada, Denmark, Finland, France, Germany, Greece, Iceland, Ireland, Italy, Japan, Luxembourg, Netherlands, Spain, Britain, United States, Czech Republic, Lithuania, Slovenia, and Poland. Nondemocracies or weak democracies included the following countries: Albania, Argentina, Bangladesh, Bulgaria, Belarus, Chile, China, India, Mexico, Moldova, Morocco, Peru, Philippines, Russia, Singapore, Vietnam, South Africa, Zimbabwe, Uganda, Ukraine, Macedonia, Tanzania, and Venezuela.
} 
TABLE 2 Determinants of Citizenship Behavior in Established Democracies

\begin{tabular}{|c|c|c|c|c|}
\hline Independent Variables & Political Discussion & Membership & Political Interest & Interpersonal Trust \\
\hline \multicolumn{5}{|l|}{ Fixed Effects } \\
\hline \multirow[t]{2}{*}{ Ethnic heterogeneity } & -.133 & .335 & .047 & $-.218^{\star}$ \\
\hline & $(.189)$ & $(.818)$ & $(.276)$ & $(.124)$ \\
\hline \multirow[t]{2}{*}{ Linguistic heterogeneity } & -.171 & -.431 & $-.827^{\star *}$ & -.007 \\
\hline & $(.206)$ & $(.894)$ & $(.301)$ & $(.135)$ \\
\hline \multicolumn{5}{|l|}{ Micro-level controls } \\
\hline \multirow[t]{2}{*}{ Local/regional identity } & $-.045^{\star * *}$ & $-.040^{\star *}$ & $-.104^{\star * *}$ & $-.019^{\star *}$ \\
\hline & $(.008)$ & $(.018)$ & $(.011)$ & $(.006)$ \\
\hline \multirow[t]{2}{*}{ Male } & $.164^{\star * \star}$ & $.028^{\star}$ & $.292^{\star * *}$ & $.009^{\star}$ \\
\hline & $(.007)$ & $(.017)$ & $(.010)$ & $(.005)$ \\
\hline \multirow[t]{2}{*}{ Age 15-34 } & $-.175^{\star * *}$ & $-.212^{\star * *}$ & $.168^{\star * *}$ & $-.050^{* * *}$ \\
\hline & $(.009)$ & $(.021)$ & $(.013)$ & $(.007)$ \\
\hline \multirow[t]{2}{*}{ Age 55-98 } & $.029^{* * *}$ & .014 & $.168^{\star * *}$ & .001 \\
\hline & $(.009)$ & $(.021)$ & $(.013)$ & $(.007)$ \\
\hline \multirow[t]{2}{*}{ High education } & $.372^{\star * *}$ & $.751^{\star * *}$ & $.582^{* * *}$ & $.216^{* * *}$ \\
\hline & $(.011)$ & $(.025)$ & $(.015)$ & $(.008)$ \\
\hline \multirow[t]{2}{*}{ Medium education } & $.194^{\star * *}$ & $.286^{\star * *}$ & $.304^{\star * *}$ & $.093^{\star * *}$ \\
\hline & $(.009)$ & $(.020)$ & $(.012)$ & $(.007)$ \\
\hline \multirow[t]{2}{*}{ Top income } & $.099^{* * *}$ & $.446^{\star * *}$ & $.170^{\star * *}$ & $.093^{* * *}$ \\
\hline & $(.015)$ & $(.035)$ & $(.021)$ & $(.012)$ \\
\hline \multirow[t]{2}{*}{ High income } & $.053^{\star * *}$ & $.230^{\star * *}$ & $.087^{\star * *}$ & $.056^{\star * *}$ \\
\hline & $(.012)$ & $(.027)$ & $(.016)$ & $(.009)$ \\
\hline \multirow[t]{2}{*}{ Medium income } & $.016 \dagger$ & $.041^{\star}$ & .015 & .008 \\
\hline & $(.011)$ & $(.025)$ & $(.015)$ & $(.008)$ \\
\hline \multirow[t]{2}{*}{ Low income } & $.067^{\star * *}$ & $-.074^{\star *}$ & $-.073^{\star * *}$ & $-.014 \dagger$ \\
\hline & $(.012)$ & $(.029)$ & $(.017)$ & $(.009)$ \\
\hline \multirow[t]{2}{*}{ Student } & .001 & $.182^{\star * *}$ & $.097^{\star \star *}$ & $.069^{\star * *}$ \\
\hline & $(.016)$ & $(.037)$ & $(.022)$ & $(.012)$ \\
\hline \multirow[t]{2}{*}{ Large town } & $.045^{\star * *}$ & $-.103^{\star * *}$ & $.070^{\star * *}$ & $-.010 \dagger$ \\
\hline & $(.010)$ & $(.023)$ & $(.014)$ & $(.008)$ \\
\hline \multirow[t]{2}{*}{ Medium town } & .005 & -.023 & .007 & .000 \\
\hline & $(.010)$ & $(.023)$ & $(.014)$ & $(.008)$ \\
\hline Catholic & .003 & $.177^{\star * *}$ & $.022 \dagger$ & -.006 \\
\hline & $(.010)$ & $(.023)$ & $(.014)$ & $(.007)$ \\
\hline Protestant & -.001 & $.447^{\star * *}$ & $.076^{\star * *}$ & $.033^{\star *}$ \\
\hline & $(.015)$ & $(.034)$ & $(.020)$ & $(.011)$ \\
\hline Muslim & $.071 \dagger$ & .077 & .060 & -.049 \\
\hline & $(.050)$ & $(.116)$ & $(.070)$ & $(.038)$ \\
\hline Orthodox & .025 & .094 & -.021 & $-.057^{\star}$ \\
\hline & $(.041)$ & $(.096)$ & $(.057)$ & $(.031)$ \\
\hline Other religion & $.037^{\star *}$ & $.529^{* * *}$ & $.070^{* *}$ & .001 \\
\hline & $(.018)$ & $(.040)$ & $(.024)$ & $(.013)$ \\
\hline Macro-level controls & & & & \\
\hline GDP per capita (in 1,000 s of & .003 & $.030 \dagger$ & $.016^{* *}$ & $.005 \dagger$ \\
\hline \$'s) & $(.005)$ & $(.019)$ & $(.007)$ & $(.003)$ \\
\hline Economic growth (in \%) & $-.023 \dagger$ & .042 & $-.057^{\star \star}$ & .009 \\
\hline & $(.014)$ & $(.060)$ & $(.021)$ & $(.009)$ \\
\hline Expenditure (in \% of GDP) & .002 & $.072 \dagger$ & -.016 & $.020^{* *}$ \\
\hline & $(.011)$ & $(.047)$ & $(.016)$ & $(.007)$ \\
\hline Intercept & $.697^{\star *}$ & -1.384 & $1.300^{* * *}$ & -.199 \\
\hline & $(.241)$ & $(1.030)$ & $(.351)$ & $(.158)$ \\
\hline Random Effects & & & & \\
\hline Variance of random intercept & .018 & .336 & .038 & .007 \\
\hline between countries & $(.006)$ & $(.107)$ & $(.012)$ & $(.002)$ \\
\hline Within-country variance & .367 & 1.952 & .709 & .204 \\
\hline & $(.003)$ & $(.016)$ & $(.006)$ & $(.002)$ \\
\hline $\mathrm{N}$ & 29,187 & 29,400 & 29,166 & 28,209 \\
\hline Wald test $\left(\chi^{2}(21)\right)$ & $2,930.61$ & $2,040.49$ & $3,936.80$ & $1,251.80$ \\
\hline
\end{tabular}

Note: Results are mixed-effects maximum likelihood estimates using STATA 9.0's xtmixed command. Numbers in parentheses represent standard errors. Reference categories for dummy variables are: age 35-54, low education, unreported income, small town, non-religious. $\dagger p<.1$ (one-tailed); ${ }^{*} p<.1$ (two-tailed); ${ }^{* *} p<.05$ (two-tailed); ${ }^{* *} p<.001$ (two-tailed). 
Table 3 Determinants of Citizenship Behavior in Less Democratic Countries

\begin{tabular}{|c|c|c|c|c|}
\hline Independent Variables & Political Discussion & Membership & Political Interest & Interpersonal Trust \\
\hline \multicolumn{5}{|l|}{ Fixed Effects } \\
\hline \multirow{2}{*}{ Ethnic heterogeneity } & $.187 \dagger$ & -.351 & .174 & -.052 \\
\hline & $(.117)$ & $(.444)$ & $(.266)$ & $(.085)$ \\
\hline \multirow[t]{2}{*}{ Linguistic heterogeneity } & .048 & $1.037^{\star *}$ & $.477^{\star *}$ & $-.135^{\star *}$ \\
\hline & $(.091)$ & $(.344)$ & $(.206)$ & $(.066)$ \\
\hline \multicolumn{5}{|l|}{ Micro-level controls } \\
\hline \multirow[t]{2}{*}{ Local/regional identity } & $-.034^{\star * *}$ & $-.041 \dagger$ & $-.049^{\star * *}$ & -.006 \\
\hline & $(.010)$ & $(.026)$ & $(.014)$ & $(.006)$ \\
\hline \multirow[t]{2}{*}{ Male } & $218^{\star * *}$ & $.135^{\star * *}$ & $.287^{\star * *}$ & $.006 \dagger$ \\
\hline & $(.007)$ & $(.019)$ & $(.010)$ & $(.005)$ \\
\hline \multirow[t]{2}{*}{ Age 15-34 } & $-.065^{\star * *}$ & $-.059^{\star *}$ & $-.087^{\star * *}$ & $-.011^{\star \star}$ \\
\hline & $(.008)$ & $(.022)$ & $(.012)$ & $(.005)$ \\
\hline \multirow[t]{2}{*}{ Age 55-98 } & -.001 & $-.073^{\star *}$ & $.030^{* *}$ & $.017^{\star *}$ \\
\hline & $(.011)$ & $(.028)$ & $(.015)$ & $(.007)$ \\
\hline \multirow[t]{2}{*}{ High education } & $.371^{\star * *}$ & $.695^{\star * *}$ & $.417^{\star * *}$ & $.027^{\star \star *}$ \\
\hline & $(.012)$ & $(.032)$ & $(.017)$ & $(.007)$ \\
\hline \multirow[t]{2}{*}{ Medium education } & $.198^{\star * *}$ & $.313^{\star * *}$ & $.195^{\star * *}$ & .001 \\
\hline & $(.009)$ & $(.024)$ & $(.012)$ & $(.006)$ \\
\hline \multirow[t]{2}{*}{ Top income } & $.136^{\star * *}$ & $.269^{* * *}$ & $.193^{\star * *}$ & $.038^{\star *}$ \\
\hline & $(.019)$ & $(.052)$ & $(.027)$ & $(.012)$ \\
\hline \multirow[t]{2}{*}{ High income } & $.090^{\star * *}$ & $.227^{\star * *}$ & $.176^{\star * *}$ & $.013 \dagger$ \\
\hline & $(.015)$ & $(.041)$ & $(.021)$ & $(.009)$ \\
\hline \multirow[t]{2}{*}{ Medium income } & $.040^{\star *}$ & $.108^{\star \star}$ & $.145^{\star \star \star}$ & .010 \\
\hline & $(.014)$ & $(.038)$ & $(.019)$ & $(.009)$ \\
\hline \multirow{2}{*}{ Low income } & $.041^{\star *}$ & .050 & $.142^{\star * *}$ & -.004 \\
\hline & $(.015)$ & $(.041)$ & $(.021)$ & $(.009)$ \\
\hline \multirow[t]{2}{*}{ Student } & $-.078^{\star \star \star}$ & $.166^{\star * *}$ & -.008 & $.019^{\star *}$ \\
\hline & $(.014)$ & $(.036)$ & $(.019)$ & $(.008)$ \\
\hline \multirow[t]{2}{*}{ Large town } & -.011 & -.019 & .010 & $-.042^{* * *}$ \\
\hline & $(.010)$ & $(.027)$ & $(.014)$ & $(.006)$ \\
\hline \multirow{2}{*}{ Medium town } & $-.020^{\star}$ & -.014 & -.006 & $-.049^{\star * *}$ \\
\hline & $(.011)$ & $(.029)$ & $(.015)$ & $(.007)$ \\
\hline Catholic & .015 & $.297^{\star * *}$ & $.038^{\star *}$ & .006 \\
\hline & $(.014)$ & $(.037)$ & $(.019)$ & $(.009)$ \\
\hline Protestant & $-.051^{\star *}$ & $.474^{\star * \star}$ & -.027 & -.002 \\
\hline & $(.018)$ & $(.047)$ & $(.024)$ & $(.011)$ \\
\hline Muslim & .007 & $.318^{\star * *}$ & .016 & $.020^{\star *}$ \\
\hline & $(.015)$ & $(.049)$ & $(.022)$ & $(.010)$ \\
\hline Orthodox & $.049^{\star * *}$ & $.089^{\star *}$ & $.051^{\star *}$ & -.005 \\
\hline & $(.015)$ & $(.039)$ & $(.021)$ & $(.009)$ \\
\hline Other religion & $-.052^{\star * \star}$ & $.406^{\star * *}$ & $-.064^{\star *}$ & $.030^{* * *}$ \\
\hline & $(.015)$ & $(.040)$ & $(.020)$ & $(.009)$ \\
\hline Macro-level controls & & & & \\
\hline GDP per capita (in 1,000 s of & $-.014^{\star *}$ & $-.054^{\star \star}$ & $-.020 \dagger$ & -.001 \\
\hline$\$ ' s)$ & $(.005)$ & $(.021)$ & $(.012)$ & $(.004)$ \\
\hline Economic growth (in \%) & .004 & -.034 & $.021 \dagger$ & $.018^{\star * *}$ \\
\hline & $(.007)$ & $(.026)$ & $(.016)$ & $(.005)$ \\
\hline Expenditure (in \% of GDP) & -.001 & $-.096^{\star * *}$ & -.013 & $.009^{* *}$ \\
\hline & $(.006)$ & $(.022)$ & $(.013)$ & $(.004)$ \\
\hline Intercept & $.585^{\star * *}$ & $1.924^{* * *}$ & $.887^{* * *}$ & $.144^{\star}$ \\
\hline & $(.106)$ & $(.399)$ & $(.238)$ & $(.076)$ \\
\hline Random Effects & & & & \\
\hline Variance of random intercept & .014 & .205 & .074 & .007 \\
\hline between countries & $(.004)$ & $(.061)$ & $(.022)$ & $(.002)$ \\
\hline Within-country variance & .405 & 2.838 & .782 & .156 \\
\hline & $(.003)$ & $(.023)$ & $(.006)$ & $(.001)$ \\
\hline $\mathrm{N}$ & 31,476 & 31,093 & 31,570 & 31,143 \\
\hline Wald test $\left(\chi^{2}(23)\right)$ & $2,682.49$ & $1,048.28$ & $1,960.11$ & 145.96 \\
\hline
\end{tabular}

Note: Results are mixed-effects maximum likelihood estimates using STATA 9.0's xtmixed command. Numbers in parentheses represent standard errors. Reference categories for dummy variables are: age 35-54, low education, unreported income, small town, non-religious. $\dagger p<.1$ (one-tailed); ${ }^{*} p<.1$ (two-tailed); ${ }^{* *} p<.05$ (two-tailed); ${ }^{* *} p<.001$ (two-tailed). 
To further add in the interpretation of effects, we calculated the substantive impact of ethnic and linguistic heterogeneity on our dependent variables for the statistically significant relations reported in Tables 2 and $3 .^{20}$ These calculations are displayed graphically in Figure 2.

First, Figure 2a reveals that the effects of ethnic heterogeneity on the frequency of political discussion are trivial, and we will not consider these effects further. Second, and more importantly, the graphs show that heterogeneity has countervailing effects on membership in voluntary associations and levels of political interest in established and less democratic systems (Figures $2 \mathrm{~b}$ and $2 \mathrm{c}$ ): while heterogeneity boosts membership and political interest in less democratic systems, it diminishes political interest or leaves organizational membership unaffected in established ones. In particular, Figures $2 \mathrm{~b}$ and $2 \mathrm{c}$ show that, below the mark of .4-.5 of linguistic fractionalization where the odds of two randomly selected individuals sharing the same background are about even, established democracies have higher levels of organizational membership and political interest. Once we cross into the territory of high fractionalization, however, less democratic countries become more interested (Figure 2c) and organized (Figure 2b) than more democratic ones. This also means that, because established democracies on average have higher levels of citizenship behaviors, heterogeneity serves to elevate citizenship behaviors in weak democracies, but reduces or fails to elevate it in established ones. Further, it implies that heterogeneity serves to mobilize and politicize rather than diminish civil society in weak democracies.

The one conspicuous exception to this pattern is interpersonal trust (Figures $2 \mathrm{~d}$ and $2 \mathrm{e}$ ). While the underlying determinants differ between established and weak democracies, heterogeneity clearly diminishes trust across the board. Figure $2 \mathrm{~d}$ demonstrates that, while trust is higher in democracies that are ethnically homogeneous, people in democracies that are highly ethnically heterogeneous are no more trusting than less democratic countries that are highly heterogeneous. The reverse holds in the case of linguistic heterogeneity (Figure 2e). While trust is about the same in established and weak democracies that speak the same language, individuals are significantly less trusting in countries that are highly linguistically heterogeneous if that country is also undemocratic. Thus,

\footnotetext{
${ }^{20}$ For illustration, the effects of variables with coefficients that are statistically indistinguishable from zero are thus shown as flat lines.
}

we conclude that, when it matters, heterogeneity reduces citizenship behaviors in the established democracies. In less democratic systems the picture is more complex: Heterogeneity mostly serves to enhance citizenship behaviors, except for the noteworthy exception of interpersonal trust.

\section{Discussion}

Population heterogeneity has long been thought to influence the quality of democratic life. Most commonly, it is assumed to create difficulties for countries' chances to establish and maintain a democratic citizenry and norms of peaceful cooperation. While there is a good deal of received wisdom about the connection between population heterogeneity and civil society, there is relatively little hard evidence to go on. To help shed light on this link, this study was therefore designed to examine the impact of different manifestations of population heterogeneity (ethnicity and language) on individual-level citizenship behavior across a broad variety of countries.

Our review of the theoretical and empirical literature revealed that the relationship between heterogeneity and civil society at the cross-national level is difficult to theorize, measure, and examine. In fact, theories of ethnic conflict, as well as psychological research on patterns of and motivations for social interaction, have generated a wealth of theoretical intuitions and related evidence about how heterogeneity and citizenship behavior are connected. While much of the literature has treated ethnic and linguistic heterogeneity as two sides of the same coin, we show that there are a number of countries that are homogeneous on one dimension and heterogeneous on another (and vice versa). Thus, ethnic and linguistic heterogeneity are not synonymous. While they are correlated, they fall short of reliably mapping onto one another.

Our review also revealed that little if any existing research has systematically examined the impact of heterogeneity on citizenship behavior from a crossnational perspective. To help fill this gap and make the test of the influence of population heterogeneity on the microfoundations of democratic life as encompassing as possible, we develop the notion of citizenship behavior, which refers to behaviors and attitudes reflective of a cooperative and engaged citizenry. We also cast our net of evidence widely by analyzing data from a varied set of countries that cover a wide range of political experience, histories, cultures, and systems. As a result, our analysis examined the impact of ethnic and linguistic heterogeneity on two structural indica- 


\section{FIGURE 2 Substantive Effects of Heterogeneity on Citizenship Behavior}
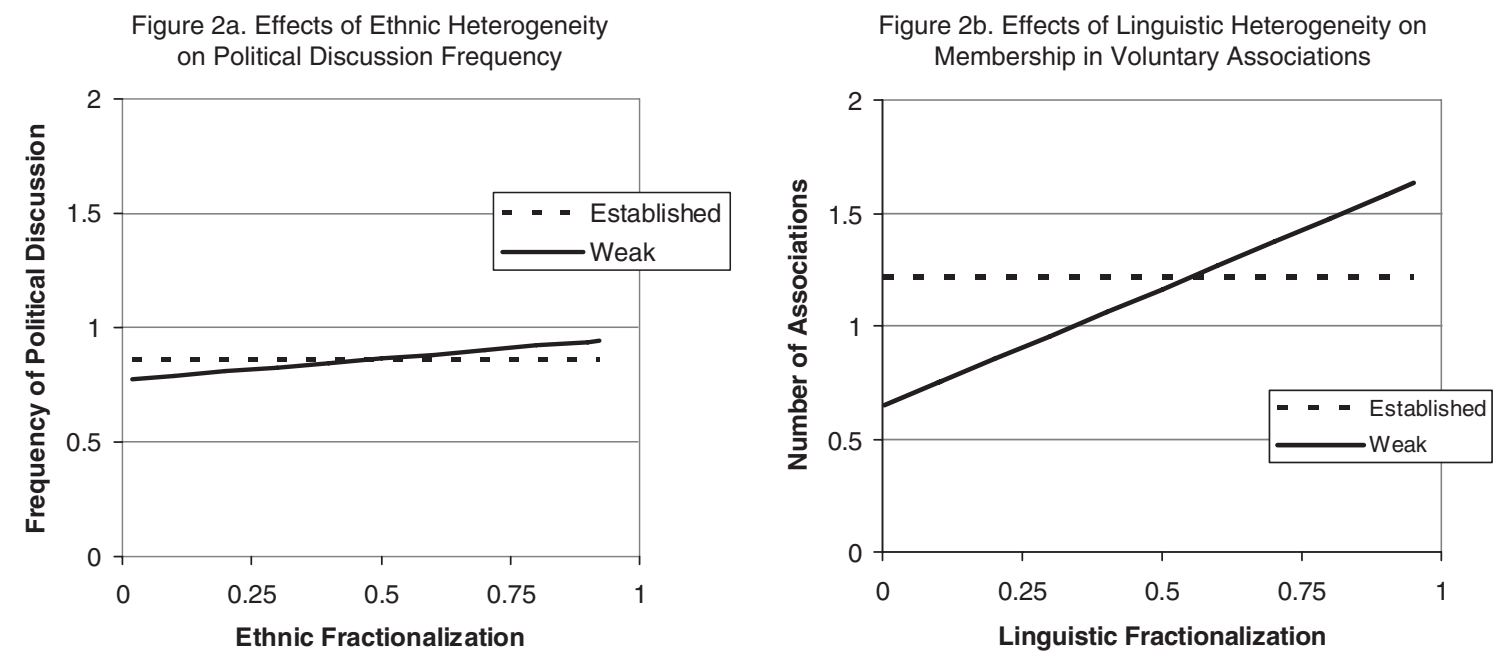

Figure 2c. Effects of Linguistic Heterogeneity on Political Interest
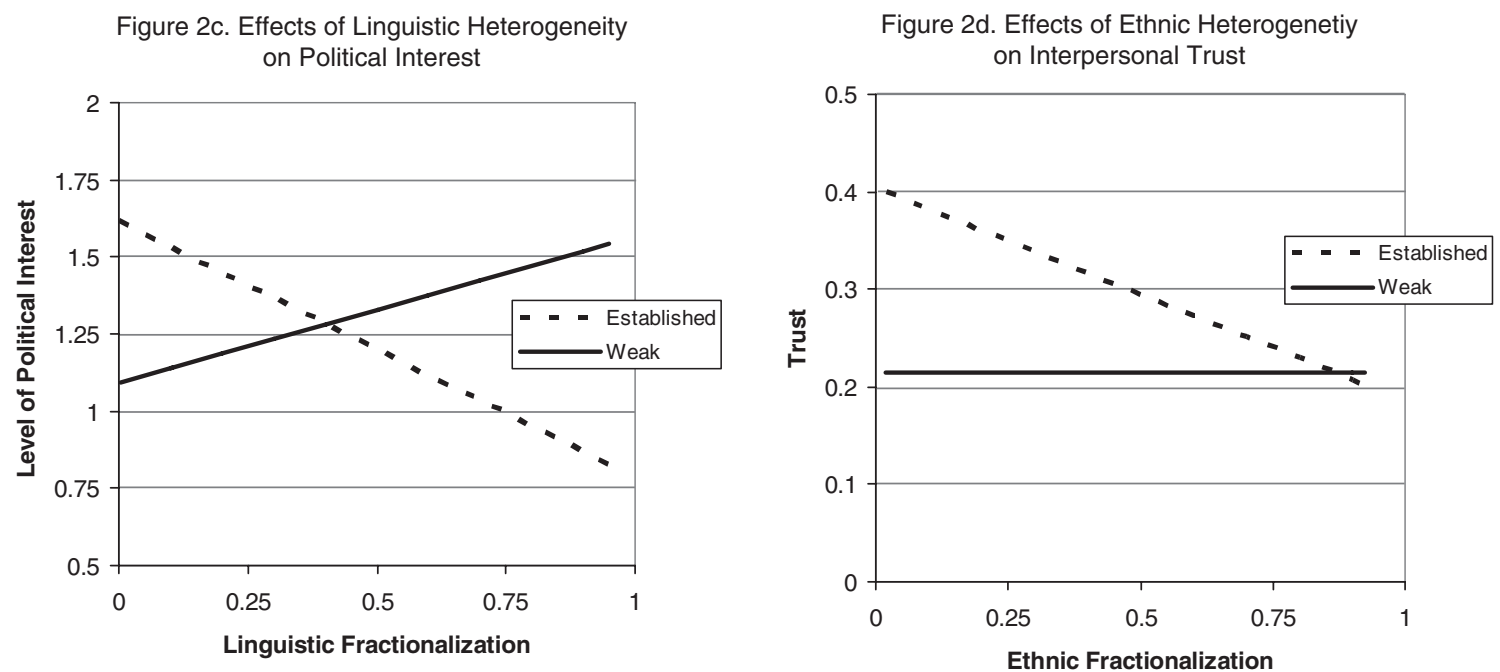

Figure 2e. Effects of Linguistic Heterogeneity on Interpersonal Trust

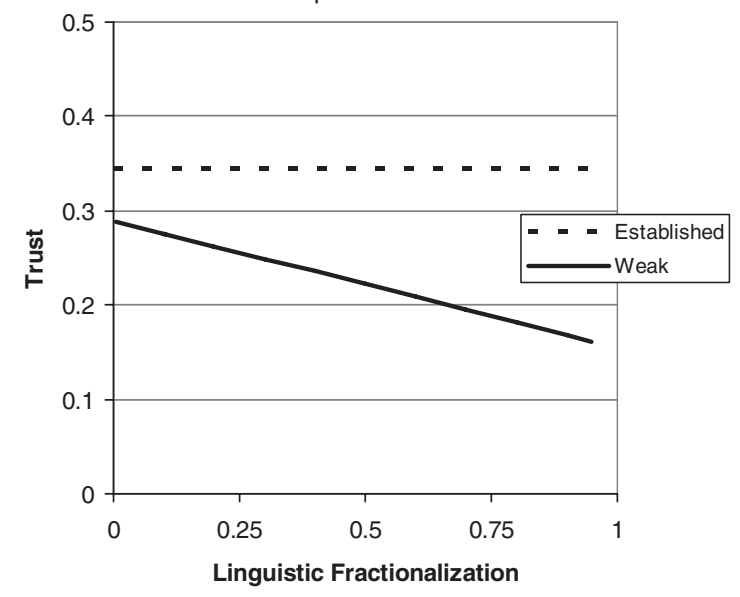

tors of citizenship behavior-political discussion frequency and organizational membership-and two cognitive indicators of citizenship-political interest and interpersonal trust-in 44 countries around the world.
As it turns out, different kinds of heterogeneity matter differently for different behaviors and attitudes associated with civil society and not always as received wisdom would anticipate. Our multivariate results indicate that increased heterogeneity actually 
leads to higher levels of some citizenship behaviors, while diminishing others. Individuals living in linguistically more heterogeneous societies are more likely to belong to voluntary associations and express an interest in politics. Moreover, individuals in societies that are ethnically heterogeneous are more likely to engage others in political discussions. However, these positive effects of heterogeneity are confined to less democratic countries. In contrast, linguistic heterogeneity diminishes people's interest in politics in established democracies.

Consistent with received wisdom about the negative effects of heterogeneity, we find that ethnic and linguistic diversity decrease levels of interpersonal trust. However, while ethnic heterogeneity decreases levels of trust in established democracies, the dimension of heterogeneity that diminishes trust in less democratic countries is language. As well, our results show that linguistic heterogeneity matters more consistently than ethnic heterogeneity. Moreover, heterogeneity has the most pronounced impact on interpersonal trust and organizational membershipcritical ingredients of civil society and behaviors associated with the provision of public goods-as well as political interest. In contrast, the effects on the frequency of political discussion-while statistically significant-were substantively small.

These results support our hypotheses only in part. While they show that heterogeneity matters, they do not support the supposition that it necessarily has a negative effect. The only dependent variable on which heterogeneity has a consistently negative influence is trust. Moreover, the results are inconsistent with the expectation that linguistic heterogeneity would have a greater and negative effect on citizenship behaviors that require social interaction and communication such as political discussion and associational membership than those that do not, such as political interest and trust.

In line with expectations, the analyses reveal that heterogeneity has a mobilizing or what one might also call politicizing effect. Yet, this finding, too, requires further explanation, as these effects are confined to the less democratic societies included in the study. Specifically, greater heterogeneity aids in recruiting members of voluntary associations, building political discussion networks, and generating citizens' interest in politics. In contrast, more heterogeneity means less interest in politics in established democracies.

Our conclusions should be considered in light of the study's limitations. It is important to bear in mind that the effects we report are the result of comparisons across the specific set of countries included in our study. And although our sample includes a varied set of states from Asia, the Americas, North America, Africa, and Europe (East and West), we cannot exclude the possibility that a different set of countries may produce different results. In addition, we wish to note that our findings are generated at a high level of aggregation and thus derive from differences in overall probabilities to engage in various behaviors. That is, they are based on the fact that, in terms of simple probabilities, it is likely that any randomly chosen group of individuals in a more heterogeneous country is relatively more heterogeneous than any randomly chosen group in a more homogeneous country. In this way, the macroenvironment affects the overall odds of encountering someone with the same ethnic or linguistic background and thus shapes the odds of the macroenvironment reproducing itself at the micro level.

This also means that our data or research design do not allow us to examine the microlevel mechanisms that give rise to the effects we report. We suspect that several different microlevel processes underlie the overall effects we report and would like to suggest that future studies focus on how different microlevel processes (interaction, spatial segregation, conflict, etc.) give rise to different combinations of aggregate level effects of heterogeneity on citizenship behavior. These questions are important insofar they would allow us to pinpoint the different causal mechanisms that produce the effects of heterogeneity we see, as well as whether these differ in more and less democratic countries.

Despite these limitations, our results have a number of empirical, theoretical, and practical implications. Empirically speaking, they imply, at a minimum, that different types of heterogeneity require empirical separation. And they suggest strongly the need to make sure that we use the appropriate measure of heterogeneity for testing the relationships presumed to be at work (cf. Posner 2004). Moreover, they lead to the simple, but critical conclusion that examining the effects of heterogeneity on democracy is complex and eschews easy categorization and summary. As so often, the world is more complex than handy generalizations imply. In particular, our results reveal that the effects of heterogeneity depend on where one looks - that is, depending on which kind of citizenship behavior is examined, which kind of heterogeneity is considered, and whether we look for evidence in more or less democratic countries.

Moreover, finding that citizens in heterogeneous but less democratic societies exhibit higher levels of some of the behaviors associated with democratic citi- 
zenship could mean that heterogeneity does not necessarily breed the risk of instability for a political system along with acrimony, hostility, or violence. Normative theorists and empirical researchers alike have argued that heterogeneity may contribute to effective democracy by broadening the range of readily available or imaginable choices for collective problem solving. If heterogeneity is the source of dissimilar views in society, it can benefit the inhabitants of a public sphere by encouraging greater interpersonal deliberation and intrapersonal reflection (Habermas 1989), teaching citizens "to see things they had previously overlooked" (Manin, Stein, and Mansbridge 1987, 351), expanding their understanding of others' perspectives (Price, Cappella, and Nir 2002), increasing people's levels of perceived freedom in a polity (Gibson 1992), and producing more legitimate, creative, and efficient collective decisions (Fearon 1998, 62).

Speaking generally, our findings are consistent with Fearon and Laitin's conclusion that "it appears not to be true that a greater degree of ethnic or religious diversity-or indeed any particular cultural demography-by itself makes a country more prone to civil war. This finding runs contrary to a common view among journalists, policy makers, and academics, which holds 'plural' societies to be especially conflictprone due to ethnic or religious tensions and antagonisms" (Fearon and Laitin 2003, 75; see also Laitin 2000b). In fact, they suggest that heterogeneity may be a necessary ingredient for building a vibrant and stable civil society and democratic life rather than being a prime cause of democratic distress.

Yet, the expression and reception of dissimilar views also requires that people trust one another. As it turns out, trust is in shorter supply in more heterogeneous societies, and this result is broadly consistent with the long-standing question of how to build trust among ethnic groups. On one hand, this finding leads us to caution against naïvely lauding the salutary effects of heterogeneity, as it leads to a less trusting but politicized and organized citizenry in less democratic countries. High levels of politicization and membership combined with questionable democratic credentials and potential may well undermine rather than strengthen democratic regimes. And high levels of trust within close networks but an absence of trust in strangers or those with whom individuals have weak ties may well threaten the vibrancy of cooperative relationships in a democratic society (though see Bahry et al. 2005). On the other hand, our results also indicate that it is linguistic rather than ethnic heterogeneity that reduces trust in less democratic societies.
Thus, the barriers to coordination, cooperation, and trust in less democratic countries may be overcome through communication rather than minimizing ethnic differences. Put another way, perhaps ethnic cooperation and contact is the wrong place to look when seeking to improve trust in democratizing countries. How countries and citizens can successfully overcome this dilemma should constitute the focus of further research in this area.

\section{Acknowledgments}

An earlier version of this paper was presented at the annual meeting of the Midwest Political Science Association. We are grateful to Vicki Hesli, the anonymous referees, and the editor for their generous and detailed comments. Thanks also to Matt Cleary and students in his Comparative Politics seminar at Syracuse University for their suggestions. Chris Anderson wishes to thank the Department of Politics and International Relations and Nuffield College at the University of Oxford for their hospitality while working on this project. The survey data are available as ICPSR Study No. 3975. The original collector of the data, ICPSR, and the relevant funding agency bear no responsibility for uses of this collection or for interpretations or inferences based upon such uses.

Manuscript submitted 12 April 2005

Manuscript accepted for publication 31 March 2006

\section{References}

Alesina, Alberto F., and Eliana La Ferrara. 2000. "Participation in Heterogeneous Communities." Quarterly Journal of Economics 115 (3): 847-904.

Alesina, Alberto F., and Eliana La Ferrara. 2002. "Who Trusts Others?" Journal of Public Economics 85 (2): 207-34.

Alesina, Alberto F., and Eliana La Ferrara. 2005. "Ethnic Diversity and Economic Performance." Journal of Economic Literature 43 (3): 721-61.

Alesina, Alberto F., Arnaud Devleeschauwer, William Easterly, Sergio Kurlat, and Romain T. Wacziarg. 2003. "Fractionalization." Journal of Economic Growth 8 (2): 155-94.

Alesina, Alberto F., and Enrico Spolaore. 2003. The Size of Nations. Cambridge, MA: MIT Press.

Almond, Gabriel A., and Sidney Verba. 1963. The Civic Culture. Boston: Little, Brown.

Anderson, Christopher J., and Aida Paskeviciute. 2005. "MacroPolitics and Micro-Behavior: Mainstream Politics and the Frequency of Political Discussion in Contemporary Democracies." In The Social Logic of Politics, ed. Alan S. Zuckerman. Philadelphia: Temple University Press, pp. 228-48. 
Bahry, Donna, Mikhail Kosolapov, Polina Kozyreva, and Rick K. Wilson. 2005. "Ethnicity and Trust: Evidence from Russia." American Political Science Review 99 (4): 521-32.

Barber, Benjamin. 1984. Strong Democracy. Berkeley: University of California Press.

Barnes, Samuel, and Max Kaase with Klaus Allerbeck, Barbara Farah, Felix Heunks, Ronald Inglehart, M. Kent Jennings, Hans-Dieter Klingemann, Alan Marsh, and Leopold Rosenmayr. 1979. Political Action: Mass Participation in Five Western Democracies. Beverly Hills, CA: Sage.

Barr, Abigail. 2004. "Kinship, Familiarity, and Trust: An Experimental Investigation.” In Foundations of Human Sociality: Economic Experiments and Ethnographic Evidence from Fifteen Small-Scale Societies, eds. Joseph Henrich, Robert Boyd, Samuel Bowles, Colin Camerer, Ernst Fehr, and Herbert Gintis. New York: Oxford University Press, pp. 305-34.

Bobo, Lawrence. 1988. "Group Conflict, Prejudice, and the Paradox of Contemporary Racial Attitudes." In Eliminating Racism: Profiles in Controversy, eds. P. Katz and D. Taylor. New York: Plenum Press, pp. 85-114.

Bowler, Shaun, Todd Donovan, and Robert Hanneman. 2003. “Art for Democracy's Sake? Group Membership and Political Engagement in Europe." Journal of Politics 65 (4): 1111-29.

Brehm, John, and Wendy Rahn. 1997. "Individual-Level Evidence for the Causes and Consequences of Social Capital." American Journal of Political Science 41 (3): 999-1023.

Brewer, Marilyn B. 1981. "Ethnocentrism and Its Role in Intergroup Trust." In Scientific Inquiry in the Social Sciences, eds. M. Brewer and B. Collins. San Francisco: Jossey Bass, pp. 345-59.

Cigler, Allan, and Mark R. Joslyn. 2002. "The Extensiveness of Group Membership and Social Capital: The Impact on Political Tolerance Attitudes.” Political Research Quarterly 55 (1): 7-25.

Coleman, James S. 1990. Foundations of Social Theory. Cambridge, MA: Harvard University Press.

Conover, Pamela J., Donald D. Searing, and Ivor M. Crewe. 2002. "The Deliberative Potential of Political Discussion." British Journal of Political Science 32 (1): 21-62.

Converse, Philip E. 1970. "Attitudes and Nonattitudes: Continuation of a Dialogue." In The Quantitative Analysis of Social Problems, ed. Edward R. Tufte. Reading, MA: Addison-Wesley, pp. $168-89$.

Costa, Dora L., and Matthew E. Kahn. 2003. "Civic Engagement in Heterogeneous Communities." Perspectives on Politics 1 (1): 103-112.

Curtis, James E., Douglas E. Baer, and Edward G. Grabb. 2001. "Nations of Joiners: Explaining Voluntary Association Membership in Democratic Societies." American Sociological Review 66 (6): 783-805.

Dahl, Robert A. 1971. Polyarchy, Participation, and Opposition. New Haven: Yale University Press.

Dalton, Russell J. 2002. Citizen Politics: Public Opinion and Political Parties in Advanced Western Democracies. 3rd ed. Chatham, NJ: Chatham House Publishers.

Dovidio, John F., and Samuel L. Gaertner. 1999. "Reducing Prejudice: Combating Intergroup Biases." Current Directions in Psychological Science 8 (4): 101-105.

Dowley, Kathleen, and Brian Silver. 2002. "Social Capital, Ethnicity and Support for Democracy in the Post-Communist States." Europe-Asia Studies 54 (4): 505-28.

Easterly, William, and Ross Levine. 1997. "Africa's Growth Tragedy: Policies and Ethnic Divisions." Quarterly Journal of Economics 112 (4): 1203-1250.
Elkins, Zachary, and John Sides. 2004. "In Search of the Unified Nation-State: National Attachment Among Distinctive Citizens." Presented at the Annual Meeting of the Midwest Political Science Association.

Fearon, James D. 1998. "Commitment Problems and the Spread of Ethnic Conflict." In The International Spread of Ethnic Conflict: Diffusion and Escalation, eds. David Lake and Donald Rothchild. Princeton: Princeton University Press, pp. 107-26.

Fearon, James D., and David D. Laitin. 1996. "Explaining Interethnic Cooperation." American Political Science Review 90 (4): 715-35.

Fearon, James D., and David D. Laitin. 2003. "Ethnicity, Insurgency, and Civil War.” American Political Science Review 97 (1): 75-90.

Fishkin, James S. 1991. Democracy and Deliberation. New Haven: Yale University Press.

Garcia Montalvo, José, and Martha Reynal-Quero. 2005. "Ethnic Diversity and Economic Development." Journal of Development Economics 76 (2): 293-323.

Gibson, James L. 1992. “The Political Consequences of Intolerance: Cultural Conformity and Political Freedom." American Political Science Review 86 (2): 338-56.

Gibson, James L. 2001. "Social Networks, Civil Society, and the Prospects for Consolidating Russia's Democratic Transition." American Journal of Political Science 45 (1): 51-68.

Gibson, James L., and Amanda Gouws. 2002. Overcoming Intolerance in South Africa: Experiments in Democratic Persuasion. New York: Cambridge University Press.

Giles, Micheal W., and Melanie Buckner. 1993. "David Duke and Black Threat: An Old Hypothesis Revisited." Journal of Politics 55 (3): 702-13.

Gordon, Raymond G., Jr., ed. 2005. Ethnologue: Languages of the World, 15th ed. Dallas: SIL International.

Grootaert, Christiaan, and Thierry van Bastelaer, eds. 2002. The Role of Social Capital in Development: An Empirical Assessment. New York: Cambridge University Press.

Guttman, Amy, and Dennis Thompson. 1996. Democracy and Disagreement. Cambridge, MA: Harvard University Press.

Habermas, Jürgen. 1989. The Structural Transformation of the Public Sphere. Cambridge, MA: MIT Press.

Hansen, Susan B. 1997. "Talking about Politics: Gender and Contextual Effects on Political Proselytizing." Journal of Politics 59 (1): 73-103.

Hanushek, Eric, and John Jackson. 1977. Statistical Methods for Social Scientists. San Diego: Academic Press.

Hibbs, Douglas A., Jr. 1973. Mass Political Violence. New York: John Wiley.

Horowitz, Donald. 1985. Ethnic Groups in Conflict. Berkeley: University of California Press.

Huckfeldt, R. Robert, and John D. Sprague. 1995. Citizens, Politics, and Social Communication: Information and Influence in an Election Campaign. New York: Cambridge University Press.

Inglehart, Ronald. 1999. "Trust, Well-Being and Democracy." In Democracy and Trust, ed. Mark E. Warren. New York: Cambridge University Press, pp. 88-120.

Inglehart, Ronald, and Wayne E. Baker. 2000. "Modernization, Cultural Change, and the Persistence of Traditional Values." American Sociological Review 65 (1): 19-51.

Inglehart, Ronald, et al. 2000. World Values Surveys and European Values Surveys, 1981-1984, 1990-1993, and 1995-1997 (computer file). Ann Arbor: Institute for Social Research (producer). Ann Arbor: Inter-university Consortium for Political and Social Research (distributor). 
Jennings, M. Kent. 1983. "Gender Roles and Inequalities in Political Participation: Results from an Eight-Nation Study." Western Political Quarterly 36 (3): 364-85.

Jennings, M. Kent, and Jan W. van Deth, with Samuel Barnes, Dieter Fuchs, Felix Heunks, Ronald Inglehart, Max Kaase, Hans-Dieter Klingemann, and Jacques Thomassen. 1989. Continuities in Political Action: A Longitudinal Study of Political Orientations in Three Western Democracies. New York: de Gruyter.

Jennings, M. Kent, and Richard G. Niemi. 1981. Generations and Politics: A Panel Study of Young Adults and Their Parents. Princeton: Princeton University Press.

Karlan, Dean S. 2002. "Social Capital and Group Banking.” Typescript, MIT.

Key, V. O. 1949. Southern Politics in State and Nation. New York: Knopf.

Knack, Stephen. 2002. "Social Capital and the Quality of Government: Evidence from the States." American Journal of Political Science 46 (4): 772-85.

Knack, Stephen, and Philip Keefer 1997. "Does Social Capital Have an Economic Payoff? A Cross-Country Investigation.” Quarterly Journal of Economics 112 (4): 1251-88.

Knight, Jack, and James Johnson. 1994. "Aggregation and Deliberation: On the Possibility of Democratic Legitimacy." Political Theory 22 (2): 277-96.

Krishna, Anirudh, and Norman Uphoff. 2002. "Mapping and Measuring Social Capital Through Assessment of Collective Action to Conserve and Develop Watersheds in Rajasthan, India." In The Role of Social Capital in Development: An Empirical Assessment, eds. Christiaan Grootaert and Thierry van Bastelaer. New York: Cambridge University Press, pp. 85-124.

La Ferrara, Eliana. 2002. "Inequality and Group Participation: Theory and Evidence from Rural Tanzania." Journal of Public Economics 85 (2): 235-73.

La Porta, Rafael, Florencio Lopex-de-Silanes, Andrei Shleifer, and Robert W. Vishny. 1997. “Trust in Large Organizations.” American Economic Review, Papers and Proceedings 87 (2): 333-38.

Laitin, David D. 2000a. "What is a Language Community?" American Journal of Political Science 44 (1): 142-55.

Laitin, David D. 2000b. "Language Conflict and Violence." In International Conflict Resolution After the Cold War, eds. Paul C. Stern and Daniel Druckman. Washington: National Academy Press, pp. 531-68.

Leighley, Jan E. 1990. "Social Interaction and Contextual Influences on Political Participation." American Politics Quarterly 18 (4): 459-75.

Leighley, Jan. 1995. "Attitudes, Opportunities, and Incentives: A Field Essay on Political Participation.” Political Research Quarterly 48 (1): 181-209.

Levi, Margaret. 1996. "Social and Unsocial Capital: A Review Essay of Robert Putnam's Making Democracy Work." Politics \& Society 24 (1): 45-55.

Lijphart, Arend. 1968. The Politics of Accommodation; Pluralism and Democracy in the Netherlands. Berkeley: University of California Press.

Lipset, Seymour Martin. 1994. "The Social Requisites of Democracy Revisited." American Sociological Review 59 (1): 1-22.

Macedo, Stephen, ed. 1999. Deliberative Politics: Essays on Democracy and Disagreement. New York: Oxford University Press.

MacKuen, Michael. 1990. "Speaking of Politics: Individual Conversational Choice, Public Opinion, and the Prospects for Deliberative Democracy." In Information and Democratic Processes, eds. John A. Ferejohn and James H. Kuklinski. Urbana: University of Illinois Press, pp. 55-99.
Manin, Bernard, Elly Stein, and Jane Mansbridge. 1987. "On Legitimacy and Political Deliberation." Political Theory 15 (3): 338-68.

Marschall, Melissa J., and Dietlind Stolle. 2004. "Race and the City: Neighborhood Context and the Development of Generalized Trust." Political Behavior 26 (2): 125-53.

Miguel, Edward, and Mary Kay Gugerty. 2005. "Ethnic Diversity, Social Sanctions, and Public Goods in Kenya." Journal of Public Economics 89 (11-12): 2325-68.

Muller, Edward N., and Mitchell A. Seligson. 1994. "Civic Culture and Democracy: The Question of Causal Relationships." American Political Science Review 88 (3): 635-52.

Mutz, Diana C. 2002. "Cross-Cutting Social Networks: Testing Democratic Theory in Practice." American Political Science Review 96 (1): 111-26.

Newton, Kenneth. 2001. “Trust, Social Capital, Civil Society, and Democracy." International Political Science Review 22 (2): 20114.

Nie, Norman H., Sidney Verba, and Jae-on Kim. 1971. The Modes of Democratic Participation: A Cross-National Comparison. Beverly Hills: Sage Publications.

Oliver, J. Eric., and Janelle Wong. 2003. "Intergroup Prejudice in Multiethnic Settings." American Journal of Political Science 47 (4): 567-82.

Posner, Daniel N. 2004. "Measuring Ethnic Fractionalization in Africa." American Journal of Political Science 48 (4): 849-63.

Price, Vincent, Joseph N. Cappella, and Lilach Nir. 2002. "Does Disagreement Contribute to More Deliberative Opinion?" Political Communication 19 (1): 95-112.

Putnam, Robert D. 1993. Making Democracy Work: Civic Traditions in Modern Italy. Princeton: Princeton University Press.

Putnam, Robert D. 2000. Bowling Alone: The Collapse and Revival of American Community. New York: Simon \& Schuster.

Quillian, Lincoln. 1996. "Group Threat and Regional Change in Attitudes Toward African Americans." American Journal of Sociology 102 (3): 816-60.

Raymond, Leigh. 2006. "Cooperation without Trust: Overcoming Collective Action to Endangered Species Protection." Policy Studies Journal 34 (1): 37-57.

Sniderman, Paul M., Pierangelo Peri, Rui J. P. de Figueiredo, Jr., and Thomas L. Piazza. 2000. The Outsider: Politics and Prejudice in Italy. Princeton: Princeton University Press.

Steenbergen Marco R., and Bradford S. Jones. 2002. "Modeling Multilevel Data Structures." American Journal of Political Science 46 (1): 218-37.

Stolle, Dietlind, and Marc Hooghe. 2003. "Conclusion: The Sources of Social Capital Reconsidered." In Generating Social Capital: Civil Society and Institutions in Comparative Perspective, eds. Marc Hooghe and Dietlind Stolle. New York: Palgrave Macmillan, pp. 231-48.

Stolle, Dietlind, and Thomas Rochon. 1998. "Are All Associations Alike? Membership Diversity, Associational Type, and the Creation of Social Capital." American Behavioral Scientist 42 (1): 47-65.

Tajfel, Henry, ed. 1982. Social Identity and Intergroup Relations. Cambridge: Cambridge University Press.

Taylor, Marylee C. 1998. "How White Attitudes Vary with the Racial Composition of Local Populations: Numbers Count." American Sociological Review 63 (4): 512-35.

Theiss-Morse, Elizabeth, and John R. Hibbing. 2005. "Citizenship and Civic Engagement." Annual Review of Political Science 8: $227-49$. 
Uslaner, Eric M. 2002. The Moral Foundation of Trust. New York: Cambridge University Press.

van Deth, Jan W. 1991. "Politicization and Political Interest." In Eurobarometer: The Dynamics of European Public Opinion, eds. Karlheinz Reif and Ronald Inglehart. New York: St. Martin's Press, pp. 201-13.

van Deth, Jan W. 2000. "Interesting but Irrelevant: Social Capital and the Saliency of Politics in Western Europe." European Journal of Political Research 37 (2): 115-47.

van Deth, Jan W., and Martin Elff. 2004. "Politicization, Economic Development and Political Interest in Europe." European Journal of Political Research 43 (3): 477-508.

Verba, Sidney, Kay L. Schlozman, and Henry Brady. 1995. Voice and Equality: Civic Voluntarism in American Politics. New York: Cambridge University Press.

Weingast, Barry R. 1997. "The Political Foundations of Democracy and the Rule of Law." American Political Science Review 91 (2): 245-63.
Welch, Susan, Lee Sigelman, Timothy Bledsoe, and Michael Combs. 2001. Race and Place: Race Relations in an American City. New York: Cambridge University Press.

Whiteley, Paul F. 2000. "Economic Growth and Social Capital." Political Studies 48 (3): 443-66.

Woolcock, Michael. 2001. "The Place of Social Capital in Understanding Social and Economic Outcomes." Canadian Journal of Policy Research 2 (1): 1-27.

Christopher J. Anderson is professor of government, Cornell University, Ithaca, New York 14853. Aida Paskeviciute is assistant professor of political science, Bilkent University, 06800 Bilkent, Ankara, Turkey. 